WS RC.TR $90 \cdot 393$

\title{
COMPARISON OF TRAC AND RELAP5 REACTOR SYSTEM CALCULATIONS FOR A DEGB LOCA IN K-14.1 \\ (U)
}

SEPTEMBER, 1990

11158141112

\author{
Westinghouse Savannah River Company \\ Savannah River Laboratory \\ Aiken, SC 29808
}

Prepared for the U.S. Department of Energy under Contract DE-AC09-88SR18035 
WSRC-TR---90-393

DE92 015065

NRTSC

NUCLEAR REACTOR TECHNOLOGY

AND SCIENTIFIC COMPUTATIONS

\author{
KEYWORDS: TRAC \\ RELAP \\ LOCA \\ FLOW INSTABIITY \\ K REACTOR
}

RETENTION: PERMANENT

COMPARISON OF TRAC AND RELAP5 REACTOR SYSTEM CALCULATIONS FOR A DEGB LOCA IN K-14.1 (U)

by

D. P. GRIGGS

M. L. LIEBMANN*

ISSUED: SEPTEMBER, 1990

*Wais \& Associates

$\frac{\text { Qf. Fenea }}{\text { J. P. Faraci, Authorized Derivative Classifier }}$

SRL SAVANNAH RIVER LABORATORY, AIKEN, SC 29808

Westinghouse Savannah River Company

Prepared for the U. S. Department of Energy under

Contract DE-AC09-88SR18035 
PROJECT:

DOCUMENT: WSRC-TR-90-393

TITLE: COMPARISON OF TRAC AND RELAP5 REACTOR SYSTEM CALCULATIONS FOR A DEG LOCA IN K-14.1 (U)

QA TASK NUMBER: 89-024-1

REVISION NUMBER: 0

APPROVALS
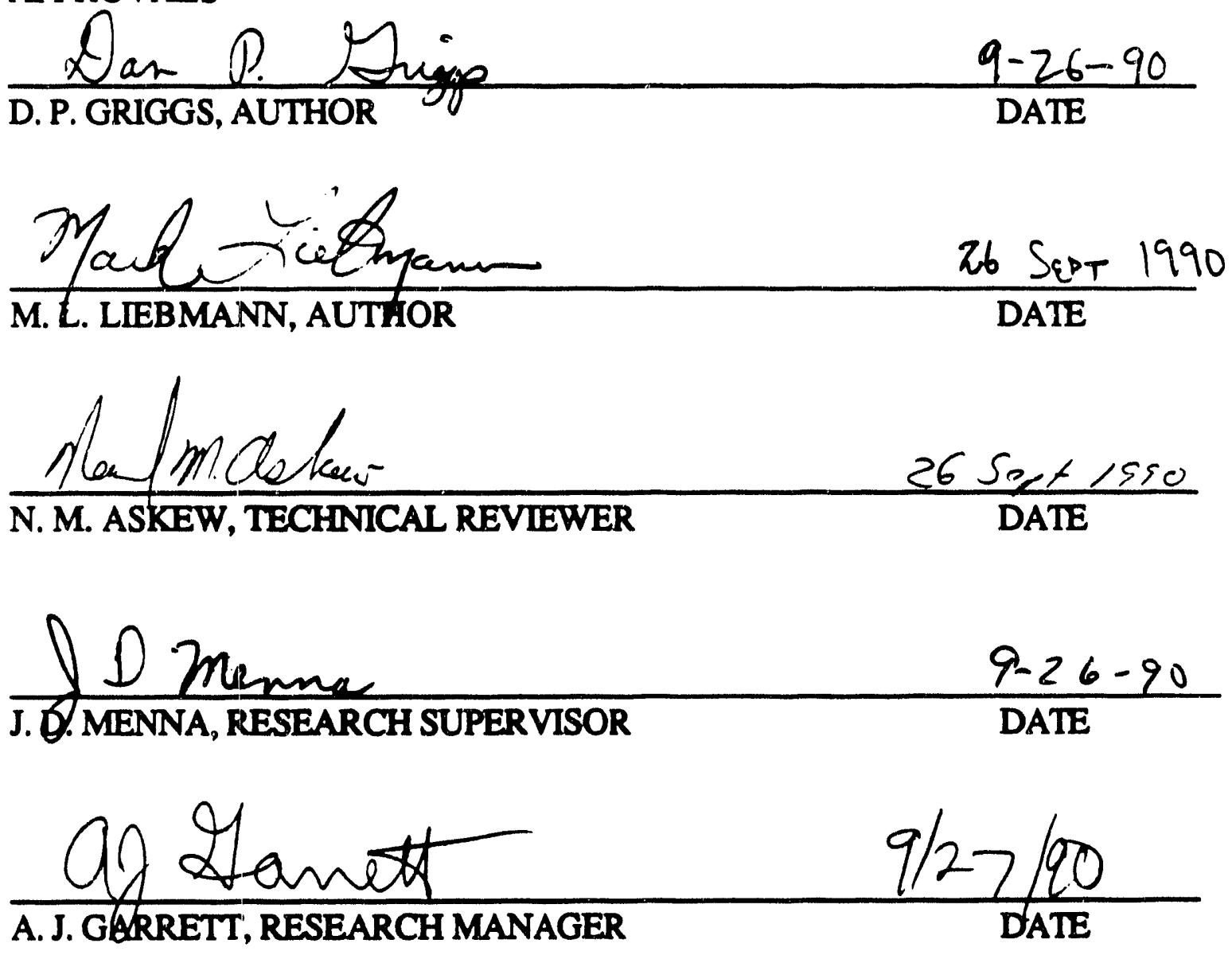


\section{TABLE OF CONTENTS}

Summary

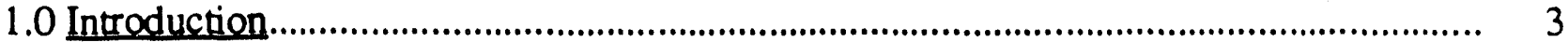

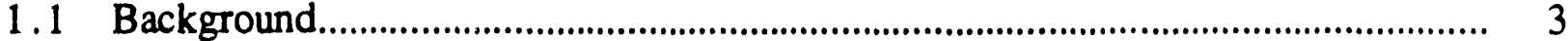

1.2 Purpose and Scope of Work......................................................................... 5

1.3 Report Organization......................................................................................... 5

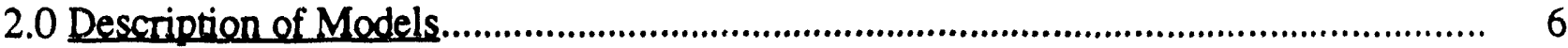

3.0 Steady-State Results.........................................................................................................

4.0 LOCA Results.................................................................................................................... 10

$4.1 \quad$ Break Flow Rates.................................................................................................... 10

4.2 Intact Loop Flow Rates...................................................................................... 11

4.3 Loop Temperatures................................................................................................. 11

4.4 Plenum Flow Rates............................................................................................... 12

4.5 Plenum Pressures................................................................................................. 13

4.6 Tank Bottom Pressures.......................................................................................... 14

4.7 Blanket Gas Space Pressure.................................................................................... 15

5.0 Conclusions and Recommendations............................................................................. 16

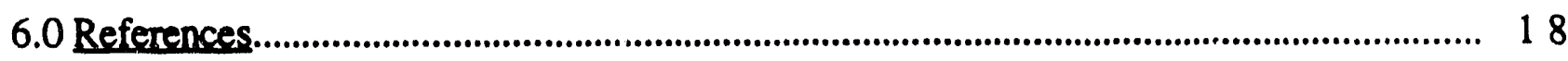

Tables

Table 3.1 Comparison of $\mathrm{K}$ Reactor Data with TRAC and RELAP5 Calculations of Steady-State Process Water

Temperatures and Flowrates.............................................. 20

Table 3.2 Comparison of $\mathrm{K}$ Reactor Data with TRAC and RELAP5 Calculations of Steady-State Plenum and Tank Bottom . Pressures.......................................................................................... 21

Table 3.3 Comparison of $\mathrm{K}$ Reactor Data with TRAC and RELAP5 Calculations of Steady-State Cooling, Water

Temperatures and Flowrates.

Eiqures

Figure 2.1 TRAC Plenum and Tank Nodalization................................ 23

Figure 2.2 RELAP5 Plenum and Tank Nodalization........................... 24

Figure 4.1 TRAC/RELAP5 K14.1 LOCA Comparison Break Flow Rates (Plenum Side).................................................................... 25

Figure 4.2 TRAC/RELAP5 K14.1 LOCA Comparison Break Flow Rates (Heat Exchanger Side). 
Figure 4.3 TRAC/RELAP5 K14.1 LOCA Comparison Loop 1 Flow Rates.

Figure 4.4 TRAC/RELAP5 K14.1 LOCA Comparison Loop 2 Flow Rates.

Figure 4.5 TRAC/RELAP5 K14.1 LOCA Comparison Loop 3 Flow Rates.

Figure 4.6

TRAC/RELAP5 K14.1 LOCA Comparison Loop 4 Flow Rates.

Figure 4.7 TRAC/RELAP5 K14.1 LOCA Comparison Loop 6 Flow Rates.

Figure 4.8 TRAC/RELAP5 K14.1 LOCA Comparison Temperatures (LOOp 1)

Figure 4.9 TRAC/RELAP5 K14.1 LOCA Comparison Temperatures (Loop 2)

Figure 4.10 TRAC/RELAP5 K14.1 LOCA Comparison Temperatures (Loop 3)

Figure 4.11 TRAC/RELAP5 K14.1 LOCA Comparison Temperatures (Loop 4)

Figure 4.12 TRAC/RELAP5 K14.1 LOCA Comparison Temperatures (Loop 5)

Figure 4.13 TRAC/RELAP5 K14.1 LOCA Comparison Temperatures (Loop 6)

Figure 4.14 TRAC/RELAP5 K14.1 LOCA Comparison Total Plenum Flow Rates.

Figure 4.15 TRAC/RELAP5 K14.1 LOCA Comparison Plenum Pressure (Break Sector, R Ring 1) ...................................... 39

Figure 4.16 TRAC/RELAP5 K14.1 LOCA Comparison Plenum Pressure (Break Sector, R Ring 2) 40

Figure 4.17 TRAC/RELAP5 K14.1 LOCA Comparison Plenum Pressure (Break Sector, R Ring 3)

Figure 4.18 TRAC/RELAP5 K14.1 LOCA Comparison Plenum Pressure (Sector 2, RELAP Ring 1) 42

Figure 4.19 TRAC/RELAP5 K14.1 LOCA Comparison Plenum Pressure (Sector 2, RELAP Ring 2)

Figure 4.20 TRAC/RELAP5 K14.1 LOCA Comparison Plenum Pressure (Sector 2, RELAP Ring 3) ...

Figure 4.21 TRAC/RELAP5 K14.1 LOCA Comparison Plenum Pressure (Sector 1, RELAP Ring 1) . 45

Figure 4.22 TRAC/RELAP5 K14.1 LOCA Comparison Plenum Pressure (Sector 1, RELAP Ring 2)

Figure 4.23 TRAC/RELAP5 K14.1 LOCA Comparison Plenum Pressure (Sector 1, RELAP Ring 3) 
Figure 4.24 TRAC/RELAP5 K.14.1 LOCA Comparison Plenum Pressure (Sector 6, RELAP Ring 1)

Figure 4.25 TRAC/RELAP5 K14.1 LOCA Comparison Plenum Pressure (Sector 6, RELAP Ring 2)

Figure 4.26 TRAC/RELAP5 K14.1 LOCA Comparison Plenum Pressure (Sector 6, RELAP Ring 3)

Figure 4.27 TRAC/RELAP5 K14.1 LOCA Comparison Tank Bottom Pressure (Sector 3, RELAP Ring 1)

Figure 4.28 TRAC/RELAP5 K14.1 LOCA Comparison Gas Plenum 


\section{COMPARISON OF TRAC AND RELAP5 REACTOR SYSTEM CAICULATIONS FOR A DEGB LOCA IN K-14.1}

\section{Summary}

A comparison of TRAC and RELAP5 predictions of steady-state and DEGB LOCA results (FI phase) for $K_{m}-14.1$ has been made. Both codes had been previously benchmarked against 1985 L Reactor AC Flow data and were under configuration control. The purpose of the codeto-code comparison is to provide insight on the transient uncertainty in TRAC plenum and tank bottom plenum pressures. The comparisons focus on LOCA results between 0.5 and $2.0 \mathrm{~s}$, which is the primary period of interest for FI limits.

On balance, the comparison of TRAC and RELAP5 steady-state and LOCA results for $\mathrm{K}-14.1$ was very favorable. Both models reflected the earlier benchmarking against $L$ reactor data; similarities and differences present in the benchmark results were in many cases present in the $\mathrm{K}-14.1$ results. The steady-state results were in good agreement. For some parameters, the agreement (in either an absolute or relative sense) between TRAC and RELAP5 LOCA results during the period of primary interest was actually better than at steady-state.

The two areas of most significant disagreement between TRAC and RELAP5 were the plenum side break flow rate and the plenum pressures in the outermost ring and in the non-break sectors of the other rings. The TRAC plenum side break flow rate was about $10 \%$ lower than predicted by RELAP5. This flow rate difference is related to differences in the plenum pressure distributions predicted by the codes. TRAC has lower plenum pressures in the sector attached to the broken nozzle; hence, the break flow rate is lower. RELAP5 has lower plenum pressures everywhere else in the plenum, particularly in the outer ring. The differences in the outer ring are similar to those seen in earlier benchmark calculations; they are not considered of great importance because outer ring pressures are not used in the limits process.

The most important plenum pressures are for the inner rings, because they are the boundary conditions used in the FI limits methodology. In particular, the break sector plenum pressure transients are used to determine the nominal flowzone deposited power limits. Here TRAC and RELAP5 agreed within 1.3 psi over the 
time period of primary interest. This is excellent agreement. The pressure transients in the non-break sectors (inner rings only) contribute to the core-wide probability of not having FI for the DEGB LOCA. The TRAC and RELAP5 results for these locations differed by 1.2 - 5.3 psi. These differences reflect an overall flatter plenum pressure distribution predicted by RELAP5.

The other parameters compared (tank bottom pressure, loop flow rates, loop temperatures, core flow rate, and blanket gas pressure) were in good to excellent agreement. In all cases, the qualitative behavior predicted by TRAC and RELAP5 was similar. 


\section{Introduction}

\subsection{Background}

TRAC-PF1/MOD1 [1] is a best estimate code that is used in the Flow Instability (FI) limits methodology [2] to perform the reactor system calculations for a double-ended guillotine break (DEGB) loss of coolant accident (LOCA). The time-dependent plenum and tank bottom pressures calculated by TRAC are used as boundary conditions for the FLOWTRAN [3] fuel assembly code. The TRAC model is a detailed representation of a production reactor, including reactor- and charge-specific core and top shield models. General features of the model are described in [4] and [5]; specific features for the K-14.1 charge are described in [6]. The model has undergone an independent geometry review, been benchmarked against reactor data [7], and been placed under configuration control.

The FI limits methodology requires quantification of the uncertainty in the nominal effluent temperature limits [8]. The uncertainties in the TRAC plenum and tank bottom pressures are major contributors to the total uncertainty from all sources. These pressure uncertainties are given in terms of one standard deviation of a normal distribution in psia for the plenum and for the tank bottom. It is these standard deviations that have to be quantified for the uncertainty analysis.

One measure of uncertainty in code results can be obtained by performing the same analysis with a different code and comparing the results. The variations in key reactor parameters resulting from differences in both the codes and the reactor models provide one measure of the uncertainty in those parameters. Furthermore, the analysis of the observed differences provides additional understanding of the sensitivities present in the LOCA predictions.

In the case of SRS production reactors, such a comparison is possible because of the existence of a RELAP5 [9] model of the reactors. This model was developed essentially independently of the TRAC model and has most of the same features, though modeled with less detail. The RELAP5 model has been benchmarked against $L$ reactor data [9] and is used in the limits methodology for the Emergency Cooling System (ECS) phase of the DEGB LOCA. 
During 1989, the Idaho National Engineering Laboratory (INEL) completed a comprarison of TRAC and RELAP5 analyses of the flow instability (FI) phase of a double-ended guillotine break (DEGB) loss of coolant accident (LOCA) for the $\mathrm{K}-14.1$ charge. The assumed location of the break was a process water line (loop 5) at the plenum inlet nozzle. This work was a cooperative effort between Savannah River Laboratory (SRL) and the Idaho National Engineering Laboratory (INEL). The TRAC analysis was performed by SRL using the TRAC-PF1/MOD1 code and a preiiminary K-14.1 model [6]. The RELAP5 analysis was performed by INEL using the RELAP5/MOD2.5 code and a preliminary 6 loop " $r, \theta$ " $\mathrm{K}-14.1$ model. INEL analyzed the results from both codes and issued a report in August 1989 comparing the TRAC and RELAP5 analyses [10].

The overall reactor response predicted by both codes was very similar. In the process of making the comparisons, INEL made improvements to the RELAP5 models of the vacuum breakers and blanket gas system after initial analyses showed discrepancies in the TRAC and RELAP5 blanket gas and tank bottom pressures. With the improved RELAP5 model, the time-dependent pressures in the break sector of the plenum calculated by TRAC and RELAP5 generally agreed to within $1 \mathrm{psi}$, while the time-dependent tank bottom pressures generally agreed to within $0.5 \mathrm{psi}$. This is very good agreement, well within the plenum and tank bottom pressure uncertainties assumed in determining assembly effluent temperature limits [8].

In the meantime, the TRAC model was modified as a result of the geometry review and re-benchmarked against $L$ reactor data [7]. The new TRAC model was used to calculate the FI phase of the LOCA [11], producing slightly different results than the preliminary model. The TRAC code and the input decks for the K-14.1 model have subsequently been placed under configuration control and the LOCA analysis has been performed again [12] for use in the final limits calculations.

Since the original comparison with TRAC was mads, the RELAP5 model has undergone a Quality Assurance (QA) review of the input ducks, performed under the INEL ES\&T Group Standard Practice Procedure 2.0 [13], and the deck and code has been placed under configuration control at INEL. A considerable amount of new work has been done with RELAP5 at SRL, including the calculation of 
system response to the DEGB LOCA for the ECS phase limits determination [14].

\subsection{Purpose and Scope of Work}

The purpose of this report is to update the earlier comparison of TRAC and RELAP5 DEGB LOCA results using the final FI limits version of the K-14.1 TRAC model with both code and model under configuration control. The RELAP5 analysis will also be redone with the QA reviewed input decks, though the results should be unchanged from the earlier comparison.

The comparison of the two codes includes both steady-state and transient calculations. In both cases, the comparison focuses on plenum and tank bottom pressures since these are the parameters used as boundary conditions by FLOWTRAN in the limits calculations and for which uncertainties must be estimated. In addition, other system variables in the external loops and blanket gas plenum are compared since they are related to plenum and tank bottom pressures.

The comparison is intended to give information on the uncertainty associated with the TRAC calculation of time-dependent plenum and tank bottom pressures. However, this report does not attempt to estimate these uncertainties.

\subsection{Report Organization}

The balance of the report is organized as follows:

Section 2.0 - brief descriptions of the models;

Section 3.0 - presentation and discussion of TRAC and RELAP5

steady-state results;

Section 4.0 - presentation and discussion of TRAC and RELAP5 LOCA results;

Section 5.0 - discussion of conclusions and recommendations;

Section 6.0 - references. 


\subsection{Description of Models}

The TRAC and RELAP5 models used to perform the steady-state and LOCA analyses of $\mathrm{K}-14.1$ are very similar at a rather basic level in that they represent all the major thermal-hydraulic features of the reactor. These features include the six individual process loops, the water plenum, the fuel assemblies and sparjets, the moderator tank, the flow paths through and around the top shield, the gas ports, the blanket gas space, the vacuum breakers, the U-tube, and the septifoil cooling system. In both models, the six process pumps are represented by average homologous curves derived from measurements taken in the actual pumps [15]. Both models represent the parallel heat exchangers in each loop as a single equivalent heat exchanger.

The TRAC and RELAP5 models differ primarily in the level of detail with which they represent the reactor. The TRAC model is significantly more detailed, both in the one-dimensional elements comprising the process loops, fuel assemblies, and vent paths, and in the multi-dimensional elements comprising the water plenum, moderator tank, and blanket gas space. Of particular significance for the comparison of LOCA results are the differences in the horizontal nodalizations of the water plenum and the moderator tank. Figures 2.1 and 2.2 show the plenum and tank nodalizations of the TRAC and RELAP5 models, respectively. Figure 2.1 shows that TRAC models the plenum and tank with six equal azimuthal sectors and five radial rings. Figure 2.2 shows that RELAP5 models the plenum and tank with six equal azimuthal sectors and three radial rings. The innermost ring (ring 1) of the RELAP5 model is equivalent to the inner 2 rings (rings 1 and 2) of the TRAC model. Similarly, the middle ring of the RELAP5 model (ring 2) is equivalent to rings 3 and 4 of the TRAC model. Ring 3 of the RELAP5 model is equivalent to ring 5 of the TRAC model.

More detailed discussions of the TRAC model are found in [4], [5], [6], and [7]. The RELAP5 model is discussed in [9] and [10]. More detailed comparisons of the models are found in [7] and [10]. 


\subsection{Steady-State Results}

The steady-state TRAC and RELAP5 results for $\mathrm{K}-14.1$ are summarized in Tables 3.1, 3.2, and 3.3. The available reactor data from similar charges (K-13.1, K-13.2) are also shown. The intent of this comparison is not to judge the adequacy of either code to calculate steady-state behavior, since the operational data is very limited and both codes have been benchmarked against much more extensive and detailed reactor data [4,7]. The intent is to identify the differences in calculated results that are present even at steadystate, so that the differences observed later in the LOCA results can be put into perspective.

Táble 3.1 shows a comparison of calculated process water volumetric flow rates and temperatures. Process water temperature data from the $\mathrm{K}-13.1$ and $\mathrm{K}-13.2$ subcycles, which were Mark 22 charges having hydraulic characteristics nominally equivalent to $\mathrm{K}-14.1$, are included. The K-13.2 data are more directly coinparable to the code results than the $\mathrm{K}-13.1$ data because of the closer match in core power. In both cases, the measurements are a "snapshot" of conditions at a particular time during the subcyisle.

In general, the agreement between the TRAC and RELAP5 results, and the K-13.2 data is excellent. The TRAC and RELAP5 pump suction temperatures for individual loops differ by less than $2{ }^{\circ} \mathrm{C}$ and the average pump suction temperatures differ by only $0.1{ }^{\circ} \mathrm{C}$. The TRAC and RELAP5 plenum inlet temperatures for individual loops differ by less than $1^{\circ} \mathrm{C}$ and the average plenum inlet temperatures differ by only $0.6{ }^{\circ} \mathrm{C}$. The measured plenum inlet and pump suction temperatures are about $3{ }^{\circ} \mathrm{C}$ lower than calculated values. As will be discussed, this reflects differences between the heat exchanger secondary conditions assumed in the models and those of K-13.2. However, the comparison of the measured and italculated average temperature rise from the plenum inlet to the pump suction is in excellent agreement, particularly the TRAC result which differs from the measurement by only $0.1{ }^{\circ} \mathrm{C}$.

Since the total core power in the K-13.2 data was the same as in the models, the agreement in average temperature rilse indicates that the codes are calculating the correct total process water mass flow rate. The TRAC and RELAPS volumetric flow rates are in very good agreement, with the RELAP5 model predicting slightly higher flows. 
The maximum discrepancy (loop 4) is less than 800 gallons per minute (gpm), a difference of $3.5 \%$. This is consistent both in magnitude and location with the respective TRAC and RELAP5 benchmark calculitions for Test "I" of the 1985 L Reactor AC Flow Tests [7,9]. The calculated total system fl Jw rates are also in excellent agreement, differing by only $1.4 \%$. Finally, TRAC and RELAP5 calculate essentially identical septifoil cooling system flow rates.

Table 3.2 shows a comparison of measured and calculated plenum pressures and a comparison of calculated tank bottom pressures. The tank bottom pressures were obtained by adjusting the calculated cell-centered pressures in the bottom tank level for the elevation head to the actual tank bottom. The only available measurement is of plenum pressure at the core centerline. Data from two different points in the charge iycle are presented to show the normal variatiun in pienum pressure that occurs. One reason for this change in plenum pressure is the growth of an oxide layer on the fuel surface, which increases core hydraulic resistance and increases plenum pressure.

Though both codes calculate plenum pressures that are averages over rather large plenum volumes, the comparison shown in Table 3.2 is meaningful. Detailed measurements of $\mathrm{L}$ Reactor plenum pressures show that the pressure is fairly flat over the region comprising TRAC rings 1 and 2 [4,7]. The RELAP5 result for ring 1 is in excellent agreement with the measured plenum centerline pressure for $\mathrm{X}-13.2$, differing by only 0.3 pounds per square inch (psi). The agreement between RELAP5 and the $\mathrm{K}-13.1$ data is very good, differing by 1.1 psi. The TRAC result for ring 1 is in good agreement with both measurements, though it is low by $1.0-1.8 \mathrm{psi}$.

Based on these limited comparisons, the RELAP5 model seems to be a better predictor of steady-state plenum pressures. However, because the plenum pressure does, on the average, increase with radial distance from the centerline, the more detailed radial nodalization of the pl aum in the TRAC model may actually penalize TRAC relative to RELAP5 in this case. Since RELAP5 ring 1 corresponds to TRAC rings 1 and 2, the average of the TRAC pressures in rings 1 and 2 provides a more consistent basis for the comparison with the measured plenum pressures. On this basis, the TRAC plenum pressure prediction is still lower than the data, but by only $0.6-1.4$ psi. 
In general, the TRAC pressure results for the interior of the plenum are lower than RELAP5 and the TRAC results for the outer ring are higher. Again, this is consistent with the codes' respective benchmark results for 1985 L Reactor AC Flow Test "I".

The comparison of calculated tank bottom pressures shows that the TRAC and RELAP5 results are in excellent agreement. The TRAC results show a radial gradient of about 0.5 psi across the tank bc:tom, while the RELAP5 results are essentially constant. The difference in calculated pressures ranges from essentially zero in the region comprising TRAC rings 1 and 2 (RELAP5 ring 1) to a maximum of $0.5 \mathrm{psi}$ in the outermost ring. In the earlier benchmark results, TP AC tank bottom pressures were higher than RELAP5 by $0.2-0.3$ psi $[7,9]$.

Table 3.3 compares measured and calculated values for heat exchanger secondary side parameters. The heat exchangers are very complicated; neither model represents the actual fow path faithfully. Furthermore, because of code limitations both analyses were performed with heavy water cooling on the secondary side rather than the light water that is actually used. These facts account for the differences seen in Table 3.3 between the calculations and the measurements. The assumed temperature of the cooling water is somewhat different in each case; hence, the outlet temperatures differ as well. Even so, the calculated values are reasonable. The TRAC and RELAP5 secondary side models agree very well, given the $1.6^{\circ} \mathrm{C}$ difference in assumed cooling water temperature. The calculated average temperature rises and total volumetric flow rates are quite consistent. The larger measured volumetric flow rate reflects the larger specific volume of light water. 


\subsection{LOCA Results}

The LOCA analyses were performed assuming an instantaneous break of the loop 5 process pipe where it connects to the plenum inlet nozzle. A scram was initiated, with appropriate delays, when the average plenum pressure in the center of the core dropped to $90 \%$ of the steady-state value. The analyses were run for 5 seconds of transient time, though the period of primary interest for FI limits is between 0.5 and 2.0 seconds.

\subsection{Break Flow Rates}

Comparisons of the TRAC and RELAP5 break volumetric flow rates for the plenum and heat exchanger sides are shown in Figures 4.1 and 4.2 , respectively. In Figure 4.1 , the flow rate changes from positive to negative in the first few tenths of a second as the initial flow into the plenum turns around and begins to flow out of the break. In Figure 4.2, the heat exchanger side flow rate remains positive because the direction of flow is unchanged, but the magnitude increases from the steady-state value because of the presence of the break. (Note: these plots were generated with significantly more points in the first second for RELAP5 than for TRAC ; hence, some of the differences portrayed during this period of rapid oscillations are attributable to the relatively coarse selection of TRAC points.)

Figure 4.1 shows that the plenum side break flow predicted by both codes exhibits the same qualitative behavior, though there are differences in timing and magnitude between the two models. In both cases, the break flow increases rapidly before settling down to a quasi-steady value. The TRAC model predicts that a quasi-steady flow rate of around $25,000 \mathrm{gpm}$ is attained within about 0.5 seconds (s). Over the remainder of the $5.0 \mathrm{~s}$ transient, the calculated break flow ranges from a minimum of about $24,100 \mathrm{gpm}$ to a maximum of about $24,700 \mathrm{gpm}$. The RELAP5 analysis predicts a break flow that increases to a high value of approximately $29,500 \mathrm{gpm}$ at around 0.3 $s$ and then decreases to a quasi-steady value of around $27,000 \mathrm{gpm}$ at about $1.0 \mathrm{~s}$. Over the remainder of the $5.0 \mathrm{~s}$ transient, the calculated break flow ranges from a minimum of about $26,500 \mathrm{gpm}$ to a maximum of about $27,400 \mathrm{gpm}$. On the average, the TRAC break flow rate is $10 \%$ below the RELAP5 flow rate during the primary period of interest. It may be coincidental, but this is consistent with 
the TRAC benchmark results for the backflow tests ("D", "E", and "J") of the 1985 L Reactor AC Flow Tests [7]. In these analyses, the flow rate calculated for the backflow loops was $7.3 \%$ to $10.3 \%$ lower than the data. However, the TRAC results for the plenum pressures in the backflow sectors were excellent. In the $\mathrm{K}-14.1$ LOCA analyses, the differences in plenum side break flow rates are consistent with differences in the TRAC and RELAP5 plenum edge pressures, which are discussed later.

The comparison of heat exchanger side break flows shown in Figure 4.2 is similar to the plenum side break. On the heat exchanger side of the break, the flow rate reflects the response of the process pump to the reduced resistance resulting from the break. Consequently, the flow rate increases rapidly before attaining a new quasi-steady value. The agreement between the two codes during the period of the rapid increase in flow is remarkable, even to the point of showing periodic dips in flow at the same times. Both codes reach their quasi-steady values at around $1.0 \mathrm{~s}$. As in the plenum side break flow, the TRAC heat exchanger break flow rate of about 29,000 gpm is less than the RELAP5 flow rate of around 29,500 gpm. Over the period of primary interest, this difference is less than $2 \%$, which is excellent agreement. Indeed, as Table 3.1 shows, the TRAC and RELAP5 heat exchanger side break flow rates are closer than the corresponding steady-state flow rates for loop 5.

\subsection{Intact Loop Flow Rates}

Figures 4.3 - 4.7 show comparisons of the transient flow rates in the intact loops calculated by TRAC and RELAPS. The response of these loops to the LOCA is similar to the heat exchanger side of the broken loop, because the effect of the break is to reduce the overall system resistance against which the process pumps must deliver flow. In general, the calculated quasi-steady flow rates are in excellent agreement. Over the time period of primary interest, the TRAC and REL.AP5 predictions of loop flow rates in loops 1, 2, 3, and 6 agree within 1.5\%. For loop 4, TRAC and RELAPS agree to within 3\% during the same period, which is better than the steady-state difference of around $4.0 \%$.

\subsection{Loop Temperatures}

Figures $4.8-4.13$ show comparisons of transient temperatures at the pump suction ("T hot") and heat exchanger outlet ("T cold") of the six 
process loops as predicted by TRAC and RELAP5. The pump suction temperatures show very little change during the LOCA. Therefore, the agreement between TRAC and RELAP5 essentially reflects that of the steady-state analyses. For loops 1 - 3, the TRAC and RELAP5 pump suction temperatures agree within $0.25{ }^{\circ} \mathrm{C}$. For loops $4-6$, the agreement is within about $1{ }^{\circ} \mathrm{C}$.

The transient results for heat exchanger outlet temperatures show some larger differences between TRAC and RELAP5. In general, both models show a small increase in temperature for the first 2 or 3 seconds followed by a gradual cooldown. The heatup reflects the decreased core flow rate that occurs prior to the scram. For the intact loops, the RELAP5 heatup is small $\left(0.4-0.7^{\circ} \mathrm{C}\right)$, while the TRAC heatup is larger $\left(1.0-1.6^{\circ} \mathrm{C}\right)$. The predicted heatup in the broken loop is somewhat larger, $1.2{ }^{\circ} \mathrm{C}$ for RELAP5 and $2.6^{\circ} \mathrm{C}$ for TRAC. This agreement is very reasonable, especially considering that the transient temperatures are not used in the limits process.

The cooldown period reflects the impact of the scram on core power. In general, the TRAC model produces a more significint cooldown than RELAP5. This region is beyond the period of primary interest and has no impact on the FI limits.

\subsection{Plenum Flow Rates}

Figure 4.14 shows a comparison of the net volumetric plenum flow rates during the LOCA as predicted by TRAC and RELAP5. This flow rate is the sum of the flow entering the plenum from the five intact loops less the flow leaving the plenum through the broken loop. The transient behavior is qualitatively similar to that of the plenum side break flow, though in a "mirror image" sense. Plenum flow decreases as break flow increases, reaching a minimum roughly when the break flow is at its maximum. Then, as the break flow decreases to its quasi-steady value, the plenum flow increases to its own quasisteady value. As shown in Figure 4.14, this behavior is most pronounced in the RELAP5 results.

The overall agreement between the TRAC and RELAP5 plenum flow results is excellent. Initially, the RELAPS plenum flow exceeds the TRAC core flow by about $2000 \mathrm{gpm}$ out of $150,000 \mathrm{gpm}(1.4 \%)$. Early in the LOCA, the difference increases briefly as the RELAP5 plenum flow drops below TRAC, reaching a maximum value of about 9600 gpm $(8.5 \%)$. As the predicted plenum flows increase to their quasi- 
steady levels, the agreement improves. During the time period of primary interest, the TRAC plenum flow continues to ex zeed the RELAP5 flow, but only by between 900 and $1900 \mathrm{gpm}$. In fact, the difference in the TRAC and RELAP5 plenum flows between $0.6 \mathrm{~s}$ and $2.0 \mathrm{~s}$ is $1 \%$ or less, which is better agreement than seen for the steady-state conditions.

\subsection{Plenum Pressures}

The transient plenum pressures during the LOCA are among the most important parameters for the determination of FI limits. The comparison of TRAC and RELAP5 results for the plenum pressures will be presented on the basis of the 3 RELAP5 radial rings, shown in Figure 2.2. For TRAC rings 1 and 2 and a particular azimuthal sector, the comparable RELAP5 pressure is from ring 1, which represents an average of the TRAC values in that sector. Similarly, for TRAC rings 3 and 4, RELAP5 ring 2 represents an average pressure for a given sector. TRAC ring 5 is directly comparable to RELAP5 ring 3 . The sector numbering convention used in this discussion is that of the TRAC model, represented in Figure 2.1 by the cell numbers in TRAC ring 1. Notice that these sector numbers do not correspond directly to the loop numbers.

Figures 4.15 - 4.17 show a comparison of TRAC and RELAP5 plenum pressures in the break sector (sector 3 ) for rings 1 - 3, respectively. These figures show that the predicted plenum pressures experience a nearly immediate significant reduction, followed by oscillations lasting a few tenths of a second. After about $0.5 \mathrm{~s}$, the changes in calculated plenum pressures are relatively small and slow for the duration of the transient. This period of relatively stable pressure behavior encompasses the $0.5-2.0 \mathrm{~s}$ period of primary interest for FI limits. All of the subsequent discussions of plenum pressures will address this time period.

The agreement between TRAC and RELAP5 results for rings 1 and 2 of the break sector, shown in Figures 4.15 and 4.16, is very good. Indeed, the agreement (in absolute terms) is slightly better than seen for the steady-state. During the period of primary interest, the RELAP5 pressure in ring 1 ranges from 0.4 to 1.0 psi lower than TRAC, while in ring 2 the RELAP5 pressure ranges from 0.8 to $1.3 \mathrm{psi}$ higher than TRAC. The largest difference is seen in ring 3, where RELAP5 is higher by 5.0 to $5.4 \mathrm{psi}$. This ring 3 comparison is a significant change from the steady-state, where the RELAP5 pressure 
is $9.5 \mathrm{psi}$ lower than TRAC. This illustrates an important difference in the TRAC and RELAP5 plenum pressure results. In general, the RELAP5 results are "flatter" than TRAC. In the break sector, the calculated pressure difference between the inner and outer ring is about 3.5 psi for RELAP5 and about 9.5 psi for TRAC. Most of this difference is seen in ring 3 , which determines the driving pressure for the break flow rate. This is consistent with the higher plenum side break flow rate calculated by RELAP5. Significant differences in ring 3 pressures, which are seen in all sectors, dre not important to FI limits in and of themselves because ring 3 does not provide boundary conditions for any fuel assemblies.

Figures 4.18 - 4.26 show comparisons of TRAC and RELAP5 plenum pressures for rings 1,2 , and 3 in sectors 2,1 , and 6 , respectively. Sector 2 is adjacent to the break sector and is symmetric with sector 4 , which is not shown. Sector 1 is $120^{\circ}$ removed from the break sector and is symmetric to sector 5 , which is not shown. Sector 6 is $180^{\circ}$ removed from the break sector, so it is "opposite" the break.

The qualitative behavior of the calculated pressures in all of these locations is similar to that of the break sector. The impact of the flatter RELAP5 pressure distribution during the LOCA can be clearly seen by comparing sectors in a given ring. The difference between TRAC and RELAP5 plenum pressures increases with azimuthal "distance" from the break sector, reaching its maximum in sector 6 , "opposite" of the break. Here, RELAP5 predicts plenum pressures that are lower than TRAC by 4.0, 5.3, and 13.6 psi for rings 1, 2, and 3 , respectively. Indeed, the RELAP5 pressures are lower than the TRAC pressures everywhere in the plenum other than the break sector.

\subsection{Tank Bottom Pressures}

The tank bottom pressures during the LOCA are also important boundary conditions for the FI limits methodology. Figure 4.27 shows a comparison of TRAC and RELAP5 tank bottom pressures during the LOCA in sector 3, ring 1 . The behavior in all other rings and sectors is very similar to that of Figure 4.27. The TRAC and RELAP5 calculated response of the tank bottom pressures is qualitatively similar. After some brief oscillations in the first few tenths of a second, the pressure drops monotonically for a period of $1.5-2.0 \mathrm{~s}$. The pressure then increases for about $1 \mathrm{~s}$ before beginning a final period of relatively gradual decrease. The lowest 
pressures are seen during the period of primary interest, before the tank is fully vented to atmosphere.

As Figure 4.27 shows, RELAP5 calculates slightly lower tank bottom pressures than TRAC for the period of primary interest. The maximum difference is only about $0.6 \mathrm{psi}$. This is very good agreement, particularly considering that the behavior of the complicated top shield and vent path models significantly influence the tank bottom pressure.

\subsection{Blanket Gas Space Pressure}

As mentioned in Section 4.6, the tank bottom pressure is directly affected by the blanket gas pressure. Figure 4.28 shows a comparison of the TRAC and RELAP5 blanket gas pressures (gage) during the LOCA. The transient response of the blanket gas pressure is qualitatively similar to the tank bottom pressure, except that the initial oscillations are absent. Both TRAC and RELAP5 show a rapid drop in pressure, leading to a vacuum after about $0.8 \mathrm{~s}$. Both models predict that the rate of depressurization slows for a time thereafter, until the pressure eventually reaches its a minimum value. The pressure then increases as the vacuum breakers clear, eventually converging to atmospheric pressure. RELAP5 predicts a lower minimum pressure $(-2.5 \mathrm{psig})$ and a later recovery time $(2.0 \mathrm{~s})$ than TRAC (-1.9 psig, $1.9 \mathrm{~s})$. This is very good agreement and entirely consistent with the tank bottom pressure comparison discussed earlier. 


\subsection{Conclusions and Recommendations}

Or balance, the comparison of TRAC and RELAP5 steady-state and LOCA results for $\mathrm{K}-14.1$ was very favorable. Both models reflected earlier benchmarking against $L$ reactor data; similarities and differences present in the benchmark results were in many cases present in the K-14.1 results. The steady-state results were in good agreement. For some parameters, the agreement (in either an absolute or relative sense) between TRAC and RELAP5 LOCA results during the period of primary interest was actually better than at steady-state.

The two areas of most significant disagreement between TRAC and RELAP5 were the plenum side break flow rate and the plenum pressures in the outermost ring and in the non-break sectors of the other rings. The TRAC plenum side break flow rate was about $10 \%$ lower than predicted by RELAP5. This flow rate difference is related to differences in the plenum pressure distributions predicted by the codes. TRAC has lower plenum pressures in the sector attached to the broken nozzle; hence, the break flow rate is lower. RELAP5 has lo'ver plenum pressures everywhere else in the plenum, particularly in the outer ring. The differences in the outer ring are similar to those seen in earlier benchmark calculations; they are not considered of great importance because outer ring pressures are not used in the limits process.

The most important plenum pressures are for the inner rings, because they are the boundary conditions used in the FI limits methodology. In particular, the break sector plenum pressure transients are used to determine the nominal flowzone deposited power limits. Here TRAC and RELAP5 agreed within 1.3 psi over the time period of primary interest. This is excellent agreement. The pressure transients in the non-break sectors (inner rings only) contribute to the core-wide probability of not having FI for the DEGB LOCA. The TRAC and RELAP5 results for these locations differed by 1.2 - 5.3 psi. These differences reflect an overall flatter plenum pressure distribution predicted by RELAP5.

The other parameters compared (tank bottom pressure, loop flow rates, loop temperatures, core flow rate, and blanket gas pressure) were in good to excellent agreement. In all cases, the qualitative behavior predicted by TRAC and RELAP5 was similar. 
The results of this comparison of TRAC and RELAP5 LOCA analyses suggest two worthwhile areas for additional work. First, it is recommended that the comparison results be factored into the estimation of uncertainty used in the FI limits analysis, particularly the uncertainty in plenum pressure. Second, it is recommended that a TRAC model be benchmarked against some of the full-tank data from the $1989 \mathrm{~L}$ Reactor tests. 


\subsection{References}

1. "TRAC-PF1/MOD1: An Advanced Best-Estimate Computer Program for Pressurized Water Reactor Thermal-Hydraulic Analysis," Los Alamos National Laboratory, Safety Code Development Group, LA10157-MS, NUREG/CR-3858, revision of 1987.

2. W. M. Massey, et al., "LOCA FI Limits Methodology," WSRC-TM-904, June 1990.

3. S. E. Aleman, et al., "FlOWTRAN: An Algorithm for Describing the Thermal-Hydraulic Behavior of SRP Assemblies," DPSTM-140, Septemüer 1989.

4. L. D. Koffman, R. E. Pevey, and A. M. White, "TRAC Calculations of the Initial Flow Decay in L-1.1," DPST-87-737, December 1987.

5. R. E. P sve; and J. W. Reece, "TRAC Model of Reactor Vent Paths," DPST-87-738, December 1987.

6. E. G. Schaub, "TRAC Calculations of the Initial Flow Decay in K14.1," DPST-89-326, June 1990.

7. D. P. Griggs and J. M. Cozzuol, "TRAC L Reactor Model: Geometry Review and Benchmarking," WSRC-TR-90-32, August 1990.

8. B. J. Hardy and A. M. White, "A Probabilistic Method for Determining Effluent Temperature Limits for Flow Instability for SRS Reactors," WSRC-TM-90-5 (DPSTM-160), June 1990.

9. M. A. Bolander and C. B. Davis, "Benchmarking the Six-Loop, ThreeDimensional RELAPS L-Reactor Model with Savannah River Reactor Test Data," Idaho National Engineering Laboratory, EG\&G Idaho, Inc., EGG-EAST-8556, August 1989.

10. C. B. Davis, "A Comparison of RELAP5 and TRAC LOCA Calculations for the K-14.1 Charge at SRS," Idaho National Engineering Laboratory, EG\&G Idaho, Inc., EGG-EAST-8608, August 1989.

11. D. P. Griggs, "TRAC Analysis of a DEGB Plenum Inlet LOCA in K14.1," Calc-Note RFICN-89-037-1-C, issued August 1990. 
12. D. P. Griggs (M. L. Liebmann), Laboratory Notebook WSRC-NB-90160 , pp. $126-146$.

13. R. B. Duffey, "Energy and Systems Technology Group Quality Program Plan," RBD-129-88, EG\&G Idaho, Inc., December 1988.

14. "DEGB LOCA ECS Power Limit Recommendation for K Reactor Restart (Position Paper to DOE Independent Review Committee)," NES-CDG-900015, WSRC Inter-Office Memorandum, August 7, 1990.

15. L. L. Hamm and M. A. Mclain, "New Bingham Pump Head Curves," DPST-85-906 (draft), August 1985. 
Table 3.1 COMPARISON OF K REACTOR DATA WITH TRAC AND RELAP5 CALCULATIONS OF STEADY-STATE PROCESS WATER TEMPERATURES AND FLOWRATES.

\begin{tabular}{|c|c|c|c|c|}
\hline Parameter, units & $\begin{array}{c}\text { TRAC } \\
(\mathrm{K} 14.1)\end{array}$ & $\begin{array}{l}\text { RELAP5 } \\
(\mathrm{K}-14.1)\end{array}$ & $\begin{array}{l}\text { RMS }^{\top} \\
(\mathrm{K}-13.2)\end{array}$ & $\begin{array}{l}\text { RDAP2 } \\
(\mathrm{K}-13.1)\end{array}$ \\
\hline $\begin{array}{c}\text { Core Power, MW } \\
\text { Pump Suction Temperatures, }{ }^{\circ} \mathrm{C} \\
\text { Loop } 1 \\
\text { Loop } 2 \\
\text { Loop } 3 \\
\text { Loop } 4 \\
\text { Loop } 5 \\
\text { Loop } 6 \\
\text { Average } \\
\text { Plet Temperatures, }{ }^{\circ} \mathrm{C} \\
\text { Loop } 1 \\
\text { Loop } 2 \\
\text { Loop } 3 \\
\text { Loop } 4 \\
\text { Loop } 5 \\
\text { Loop } 6 \\
\text { Average } \\
\text { Temperature Rise, }{ }^{\circ} \mathrm{C} \\
\text { Average } \\
\text { Pump Volumetric Flowrates, gpm } \\
\text { Loop } 1 \\
\text { Loop } 2 \\
\text { Loop } 3 \\
\text { Loop } 4 \\
\text { Loop } 5 \\
\text { Loop } 6 \\
\text { Total } \\
\text { Septifoil Coiling System Total } \\
\text { Volumetric Flowrate, gpm }\end{array}$ & $\begin{array}{r}1326.0 \\
58.8 \\
58.3 \\
59.8 \\
58.5 \\
58.1 \\
57.3 \\
58.4 \\
\\
29.2 \\
29.1 \\
29.9 \\
28.7 \\
28.7 \\
29.0 \\
29.1 \\
29.4\end{array}$ & $\begin{array}{r}1326.0 \\
58.2 \\
57.1 \\
58.9 \\
58.3 \\
58.0 \\
59.0 \\
58.3 \\
\\
29.3 \\
28.9 \\
29.8 \\
29.4 \\
29.2 \\
29.8 \\
29.4 \\
28.8\end{array}$ & $\begin{array}{l}1326.5 \\
55.1 \\
55.7 \\
56.1 \\
52.83 \\
55.2 \\
55.5 \\
55.5 \\
26.4,26.4 \\
25.3,28.1 \\
26.4,25.8 \\
26.2,25.8 \\
26.4,26.4 \\
26.6,25.2 \\
26.3 \\
29.3\end{array}$ & $\begin{array}{c}1395 . \\
57.3 \\
58.1 \\
59.2 \\
55.6^{3} \\
57.8 \\
56.9 \\
57.9 \\
\\
26.6 \\
27.0 \\
27.4 \\
26.7 \\
26.8 \\
26.2 \\
26.8 \\
31.1\end{array}$ \\
\hline
\end{tabular}

Notes 1. Reactor Monitoring System for $12 / 14 / 87$, exposure $=285887$. MWD

2. RDAP data for $3 / 23 / 87$, exposure $=12465$ MWD

3. Omitted from averages

4. Not Available 
Table 3.2 COMPARISON OF K REACTOR DATA WITH TRAC AND RELAP5 CALCULATIONS OF STEADY-STATE PLENUM AND TANK BOTTOM PRESSURES.

\begin{tabular}{|c|c|c|c|c|}
\hline Parameter, units & $\begin{array}{l}\text { TRAC } \\
(\mathrm{K} 14.1)\end{array}$ & $\begin{array}{l}\text { RELAP5 } \\
(\mathrm{K}-14.1)\end{array}$ & $\begin{array}{l}\text { RMS }^{\top} \\
(\mathrm{K}-13.2)\end{array}$ & $\begin{array}{r}\text { RDAP2 } \\
(\mathrm{K}-13.1)\end{array}$ \\
\hline $\begin{array}{c}\text { Plenum Pressure, psia } \\
\text { Ring } 1 \text { average } 3 \\
\text { Ring } 2 \text { average } \\
\text { Ring } 3 \text { average } \\
\text { Ring } 4 \text { average } \\
\text { Ring } 5 \text { average }\end{array}$ & $\begin{array}{r}77.6 \\
78.5 \\
81.7 \\
90.8 \\
109.0\end{array}$ & $\begin{array}{l}{\left[\begin{array}{l}79.7 \\
79.7\end{array}\right.} \\
{\left[\begin{array}{r}88.2 \\
88.2\end{array}\right.} \\
99.5\end{array}$ & $\begin{array}{l}79.4^{4} \\
\text { NA5 } \\
\text { NA } \\
\text { NA } \\
\text { NA }\end{array}$ & $\begin{array}{l}78.6^{4} \\
\text { NA5 } \\
\text { NA } \\
\text { NA } \\
\text { NA }\end{array}$ \\
\hline $\begin{array}{c}\text { Tank Bottom Pressure, psia } \\
\text { Ring } 1 \text { average } 3 \\
\text { Ring } 2 \text { average } \\
\text { Ring } 3 \text { average } \\
\text { Ring } 4 \text { average } \\
\text { Ring } 5 \text { average }\end{array}$ & $\begin{array}{l}28.5 \\
28.5 \\
28.4 \\
28.3 \\
28.0\end{array}$ & $\begin{array}{l}27.6 \\
27.6 \\
27.6 \\
27.6 \\
27.5\end{array}$ & $\begin{array}{l}\text { NA } \\
\text { NA } \\
\text { NA } \\
\text { NA } \\
\text { NA }\end{array}$ & $\begin{array}{l}\text { NA } \\
\text { NA } \\
\text { NA } \\
\text { NA } \\
\text { NA }\end{array}$ \\
\hline
\end{tabular}

Notes 1. Reactor Monitoring System for $12 / 14 / 87$, exposure $=285887$. MWD

2. RDAP data for $3 / 23 / 87$, exposure $=12465 \mathrm{MWD}$

3. Based on 5 TRAC rings; RELAP5 has 3 rings corresponding to TRAC rings 1 and 2, TRAC rings 3 and 4 , and TRAC ing 5.

4. Measured at plenum centerline

5. Data Not Available 
Table 3.3 COMPARISON OF K REACTOR JATA WITH TRAC AND RELAP5 CALCULATIONS OF STEADY-STATE COOLING WATER TEMPERATURES AND FLOWRATES.

\begin{tabular}{|l|r|r|r|r|}
\hline Parameter, units & $\begin{array}{r}\text { TRAC } \\
(\mathrm{K} 14.1)\end{array}$ & $\begin{array}{r}\text { RELAP5 } \\
(\mathrm{K}-14.1)\end{array}$ & $\begin{array}{r}\text { RMS } \\
(\mathrm{K}-13.2)\end{array}$ & $\begin{array}{r}\text { RDAP2 } \\
(\mathrm{K}-13.1)\end{array}$ \\
\hline Cooling Water Temperartures, ${ }^{\circ} \mathrm{C}$ & 15.6 & 14.0 & 13.2 & 13.1 \\
Inlet Average & 44.9 & 43.5 & 43.2 & NA3 \\
Outlet Average & 29.3 & 29.5 & 30.0 & NA \\
Average Temperature Rise, ${ }^{\circ} \mathrm{C}$ & 155599 & 155915 & 170480 & NA \\
\hline Total Volumetric Flow, $\mathrm{gpm}$ &
\end{tabular}

Notes 1. Reactor Monitoring System for 12/14/87, exposure $=285887$. MWD

2. RDAP data for $3 / 23 / 87$, exposure $=12465 \mathrm{MWD}$

3. Data Not Available 


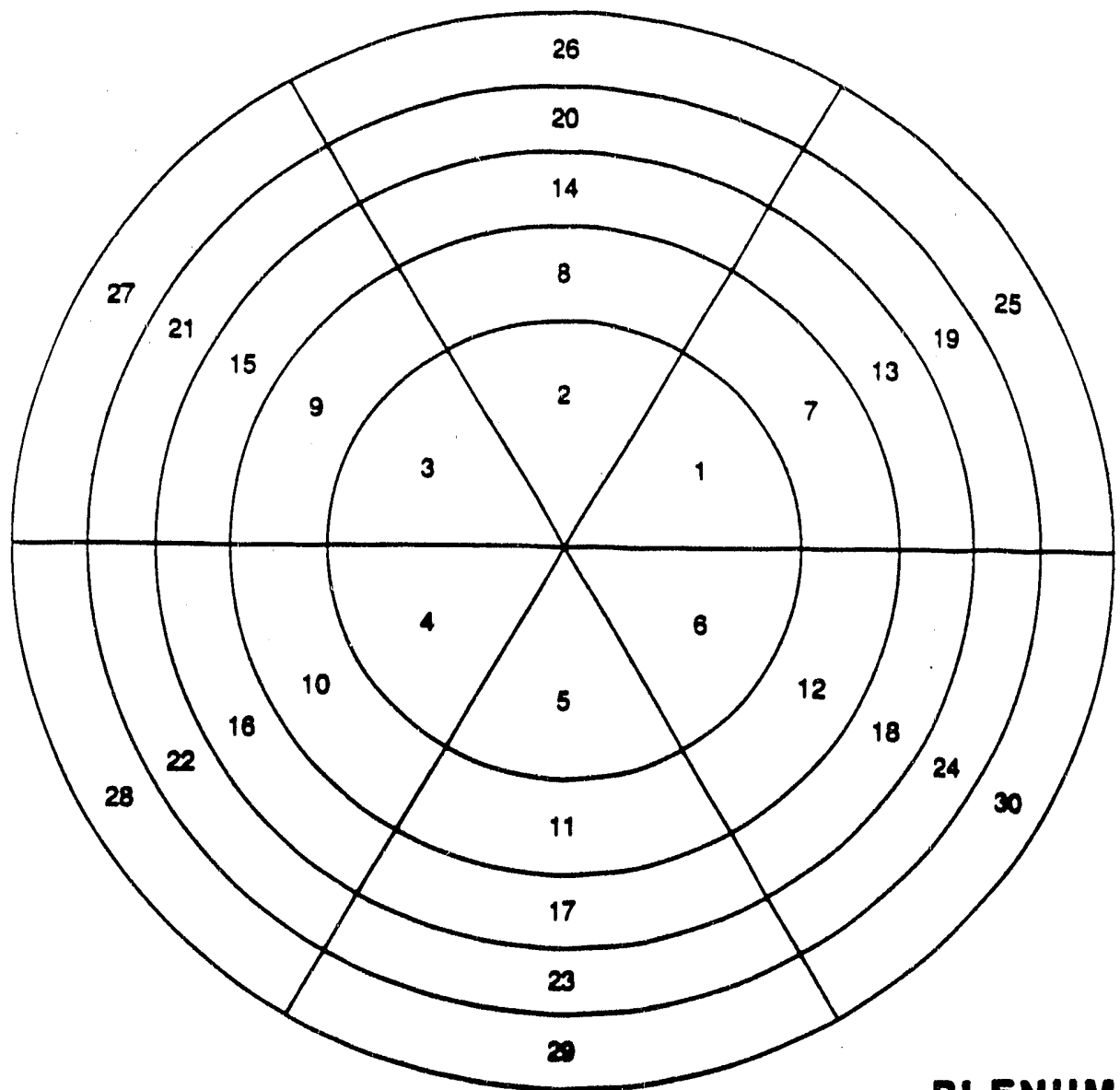

PLENUM

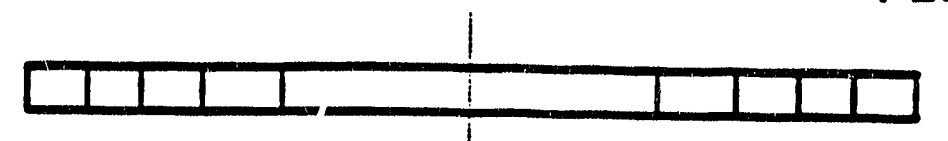

LSVE-1

MODERATOR TANK

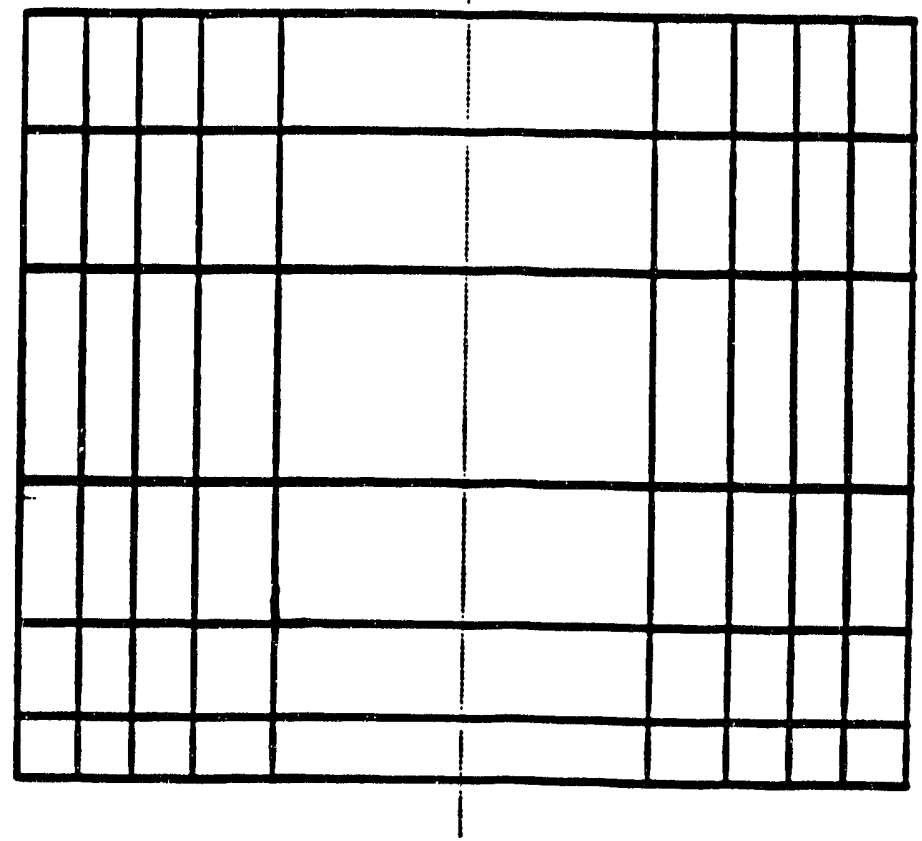

WVA 6

Lyes

LEVA

4บ3

LVI2 2

LAE 1

FIGIIRE 2.1 TRAC PI FNIIM AND TANK NODALIZATION 


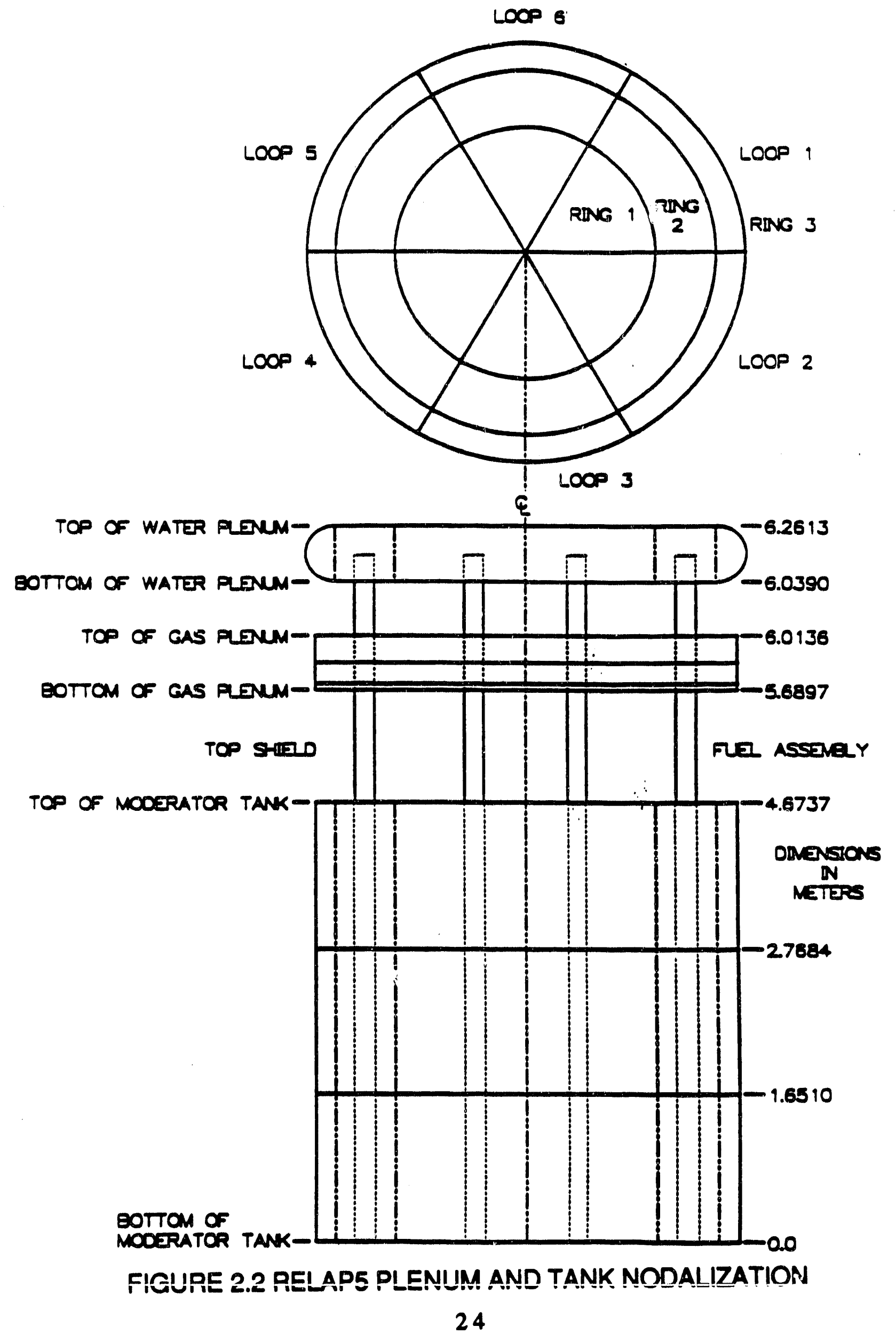




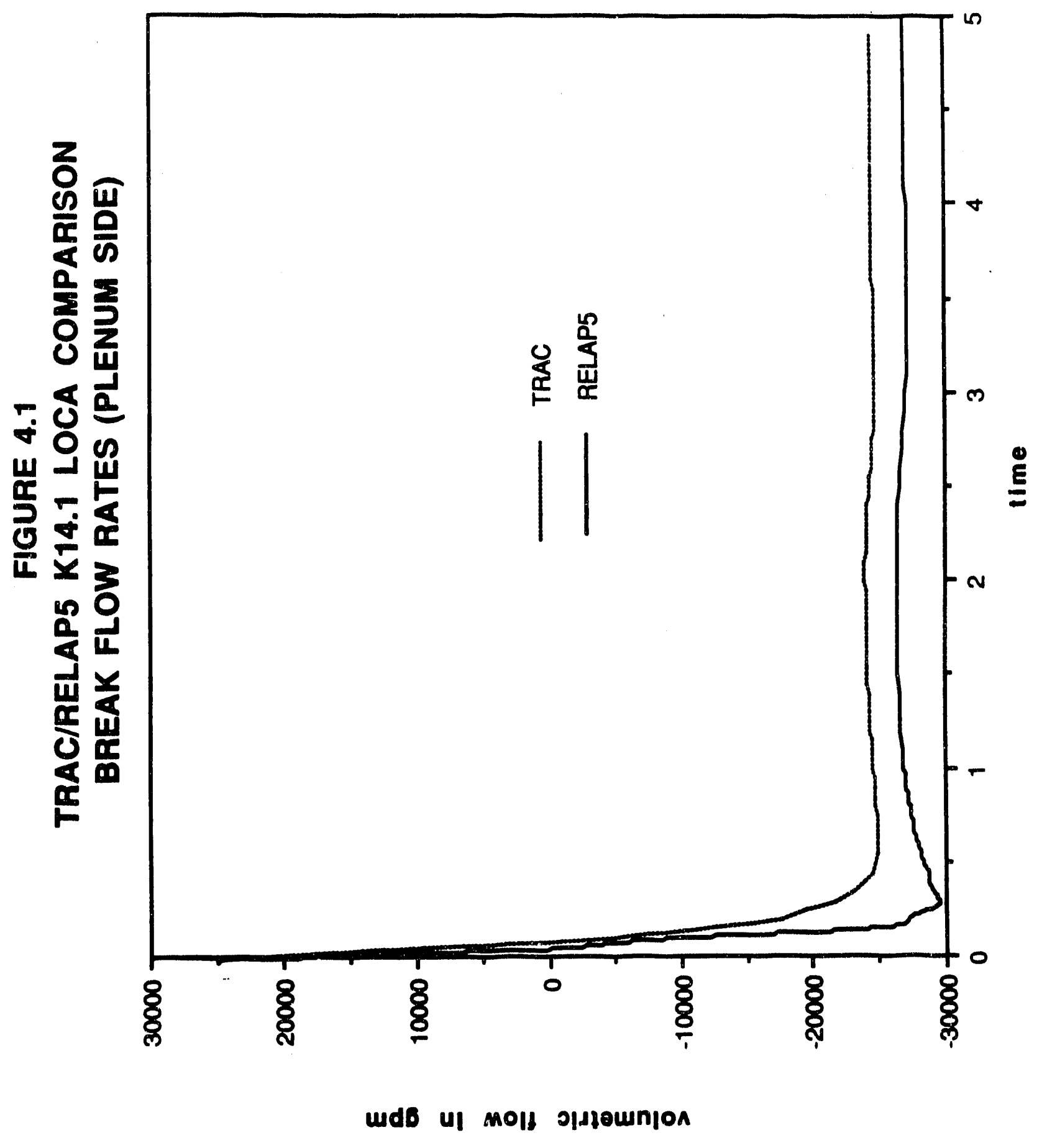




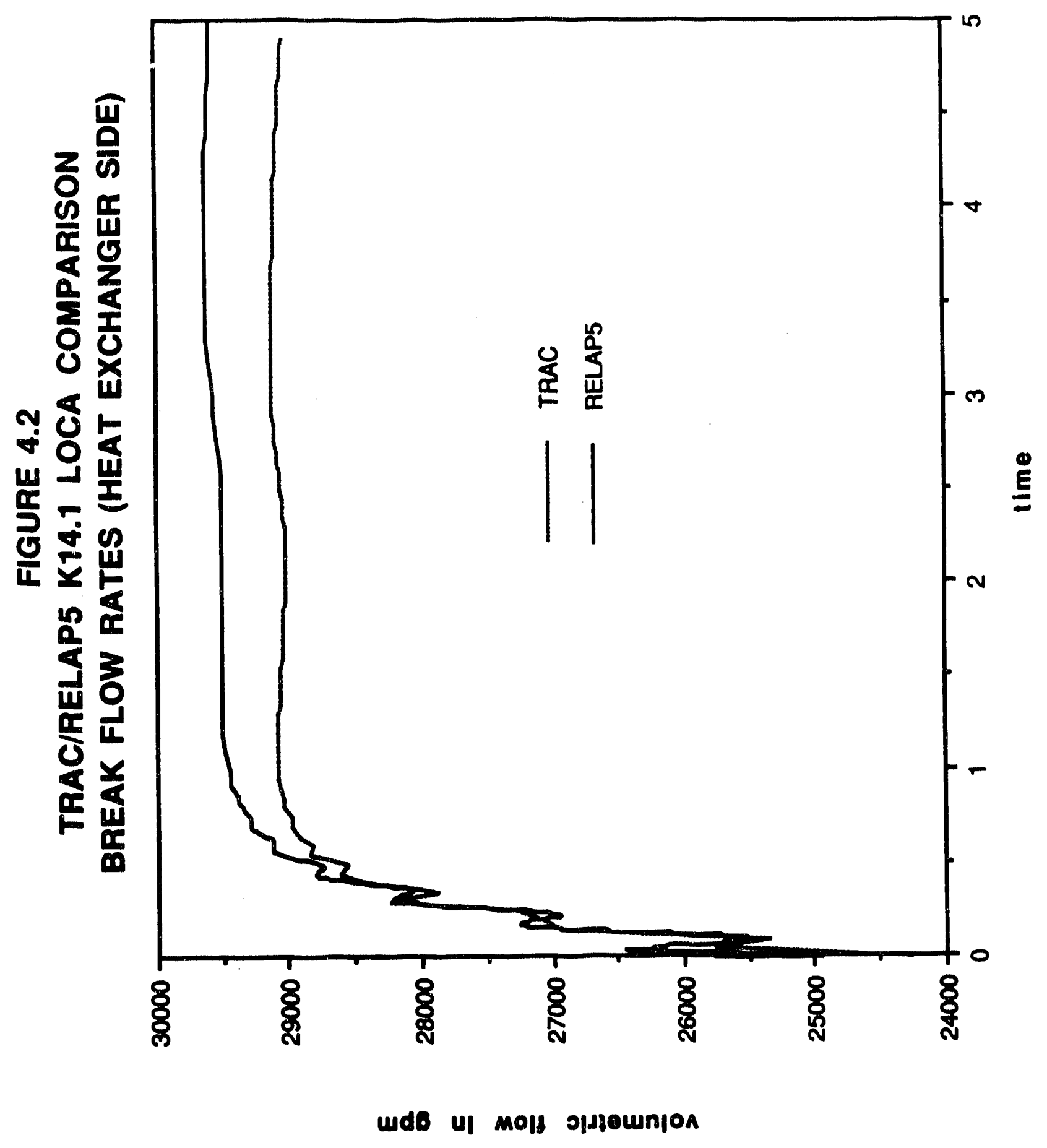




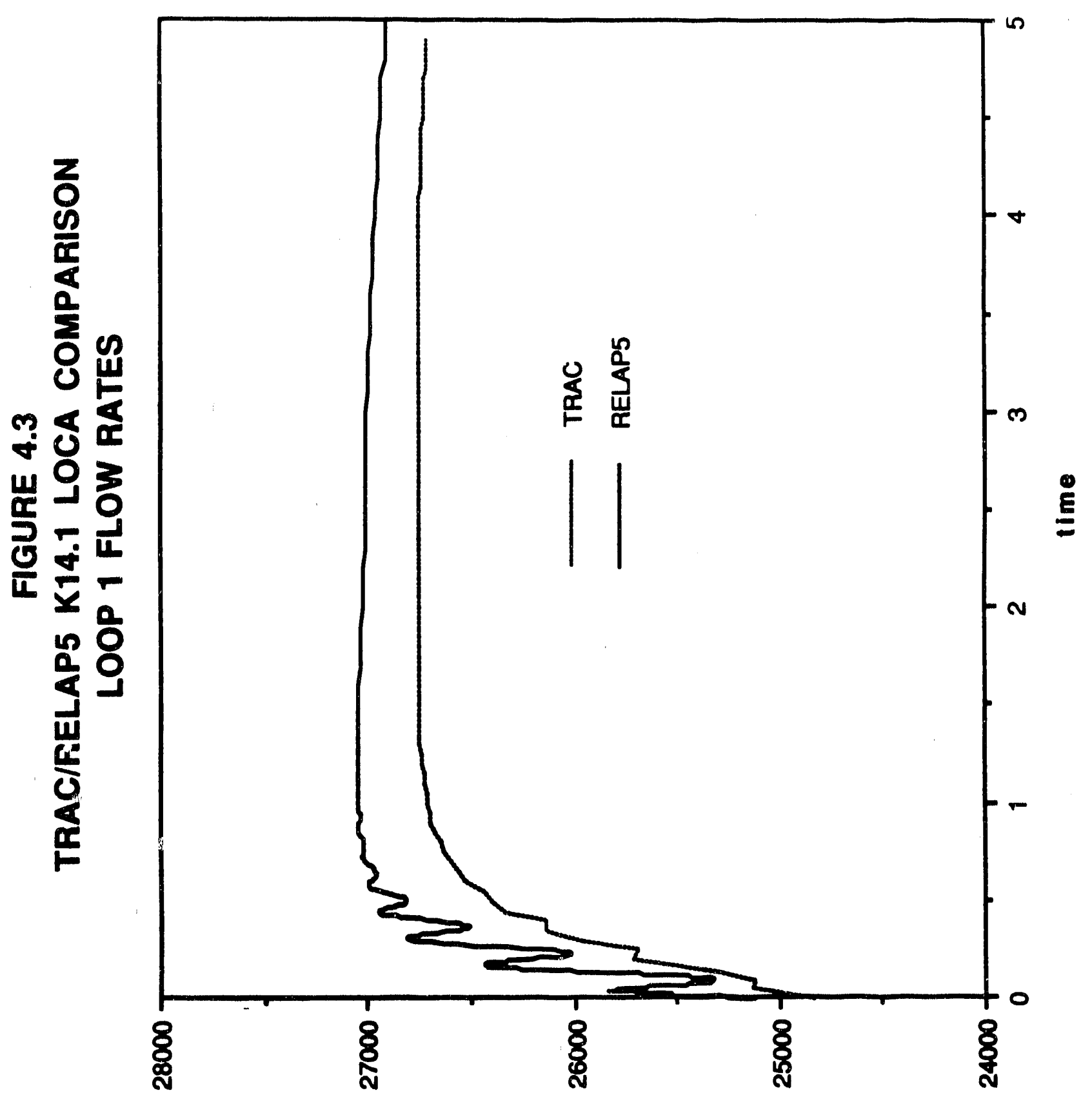

udB ul Mols opגownjon 


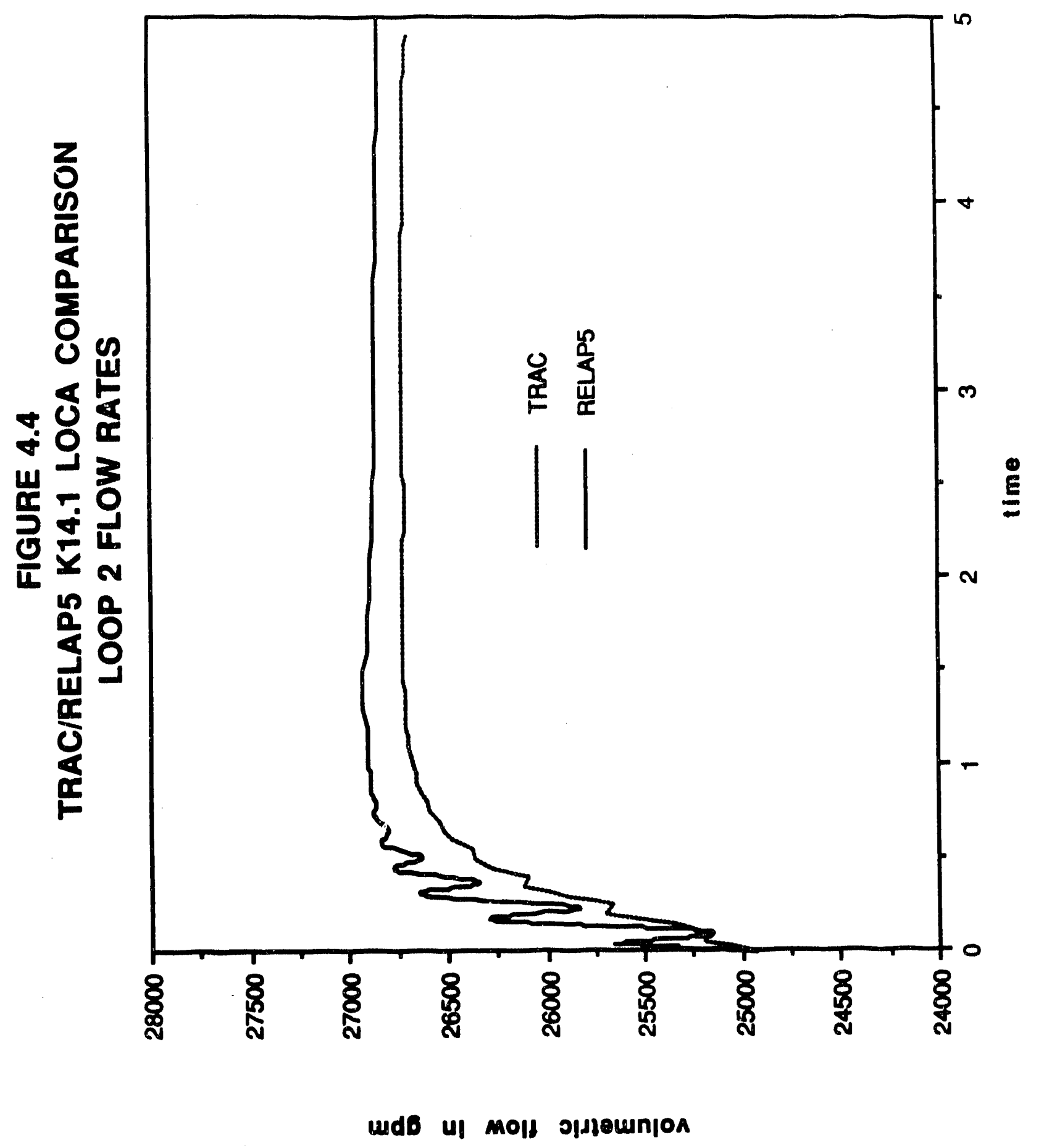




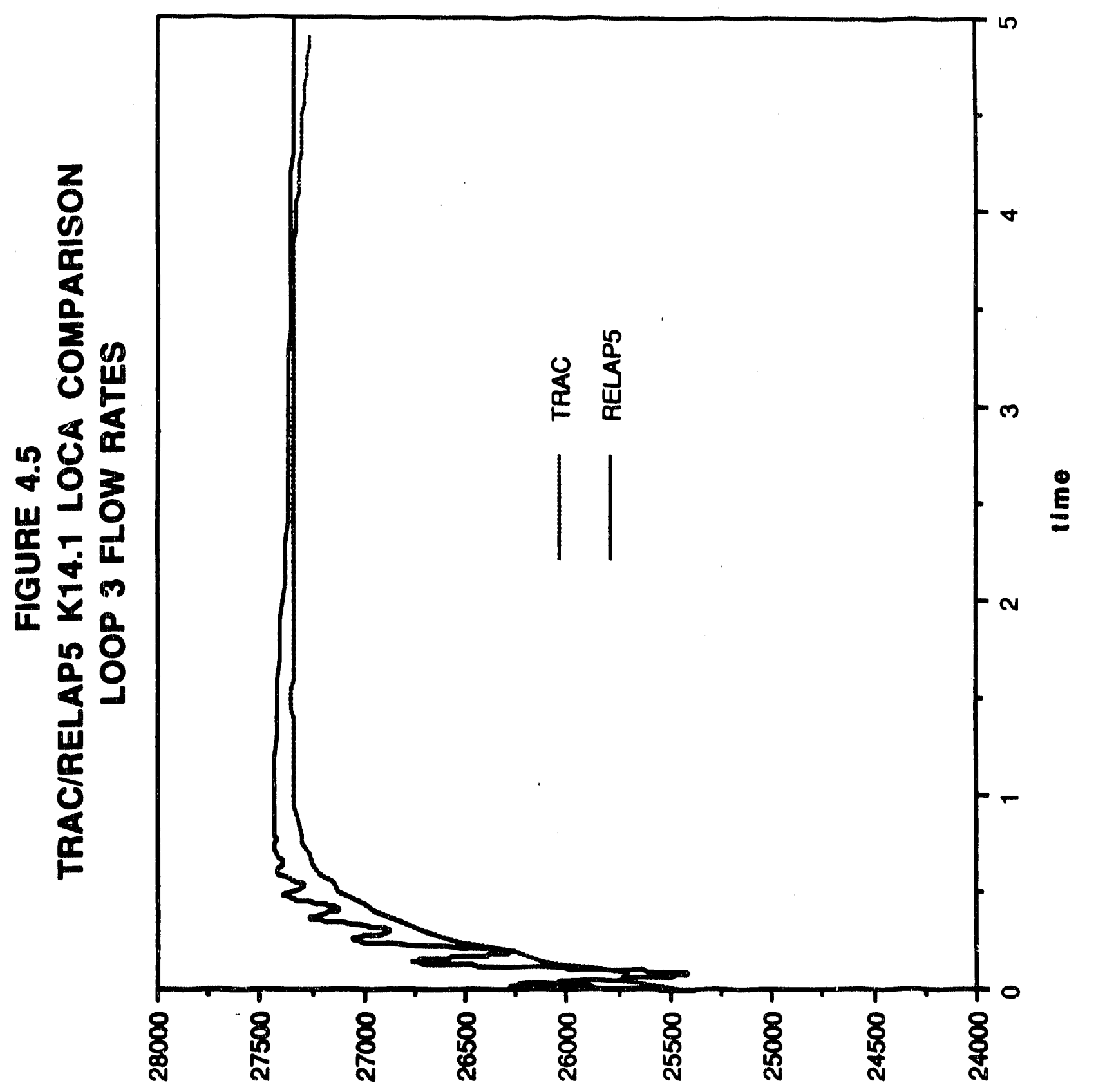

wd8 ul mols opjlounjon 


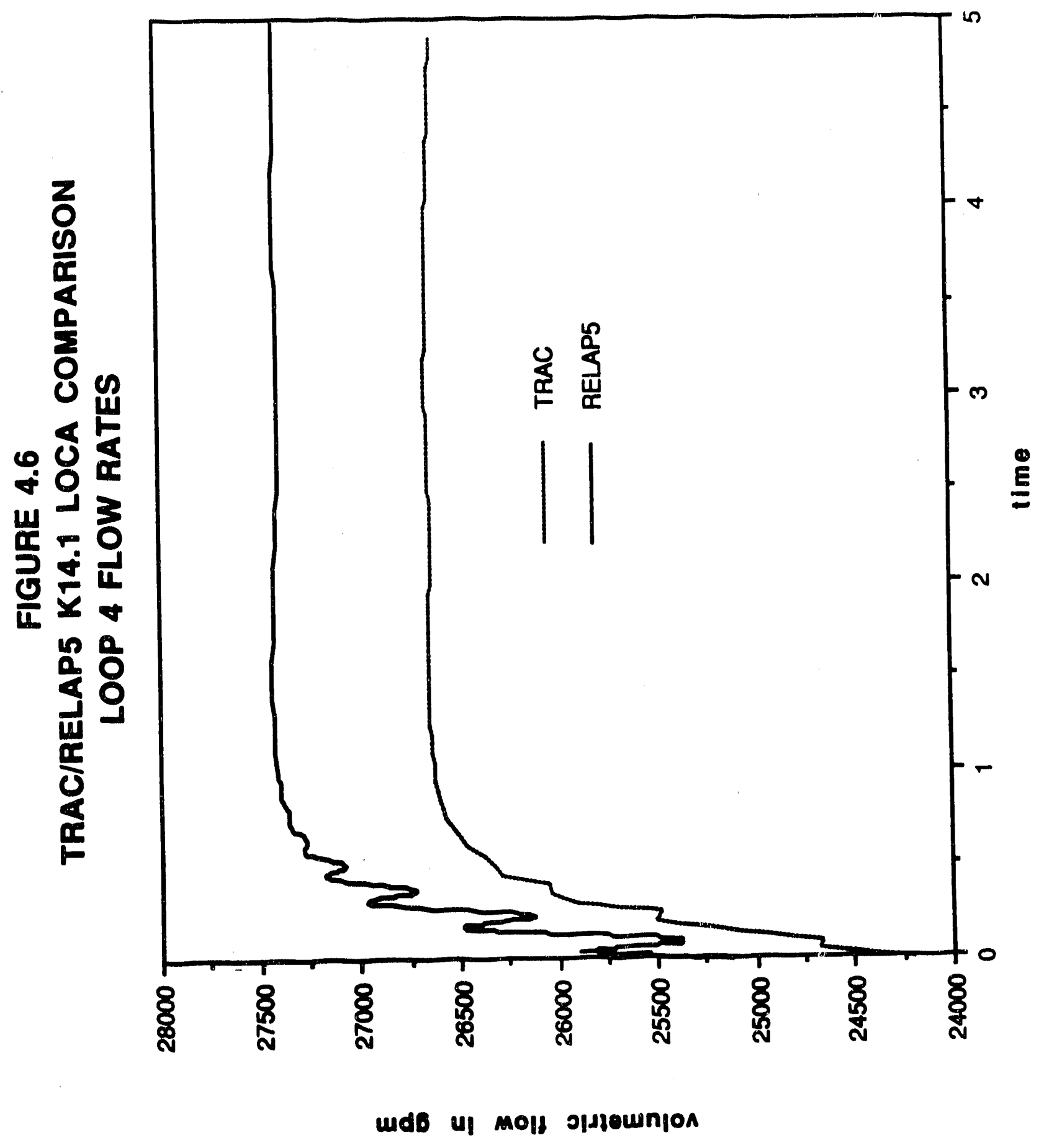




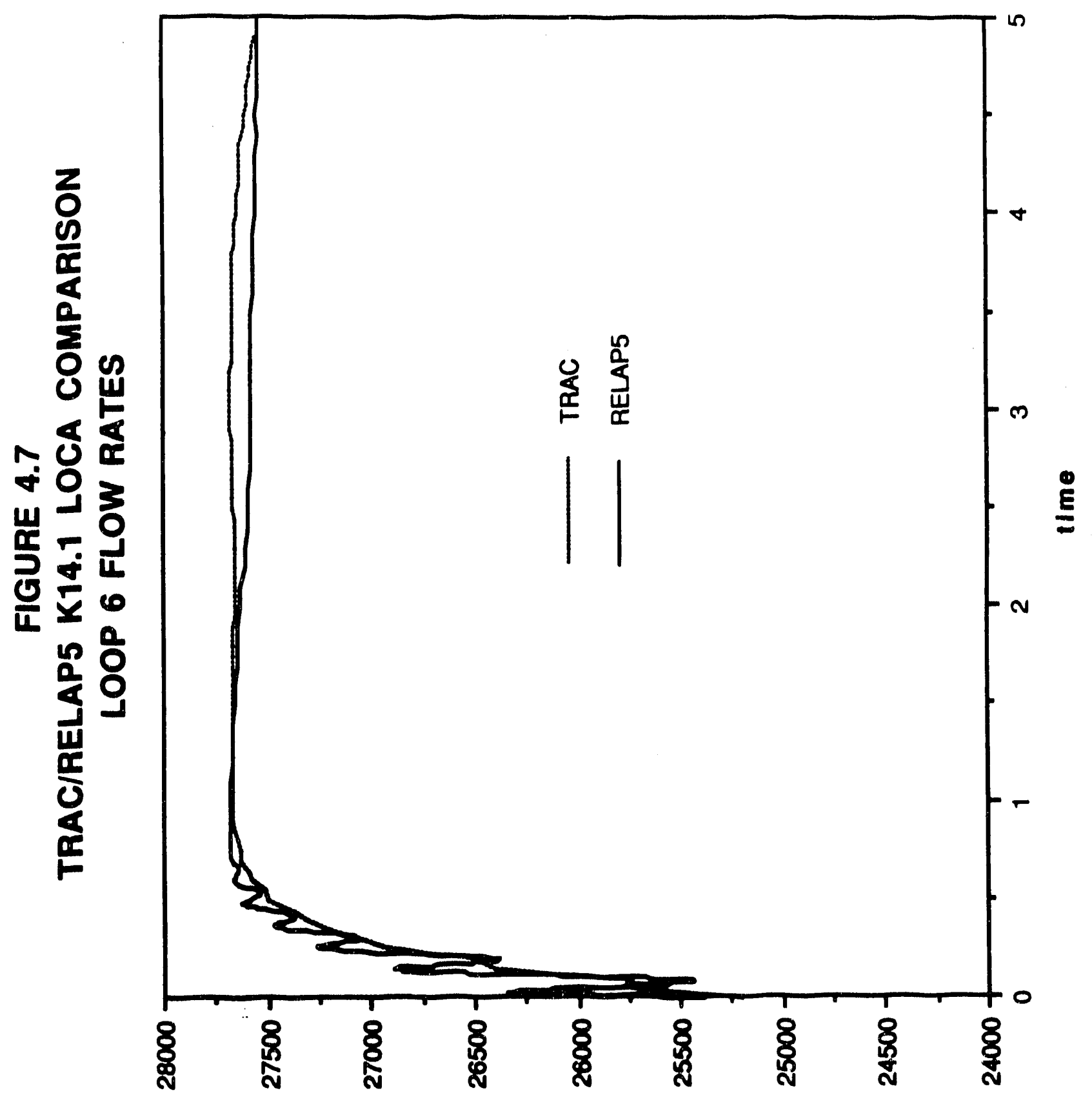

udb ul mols opslownion 


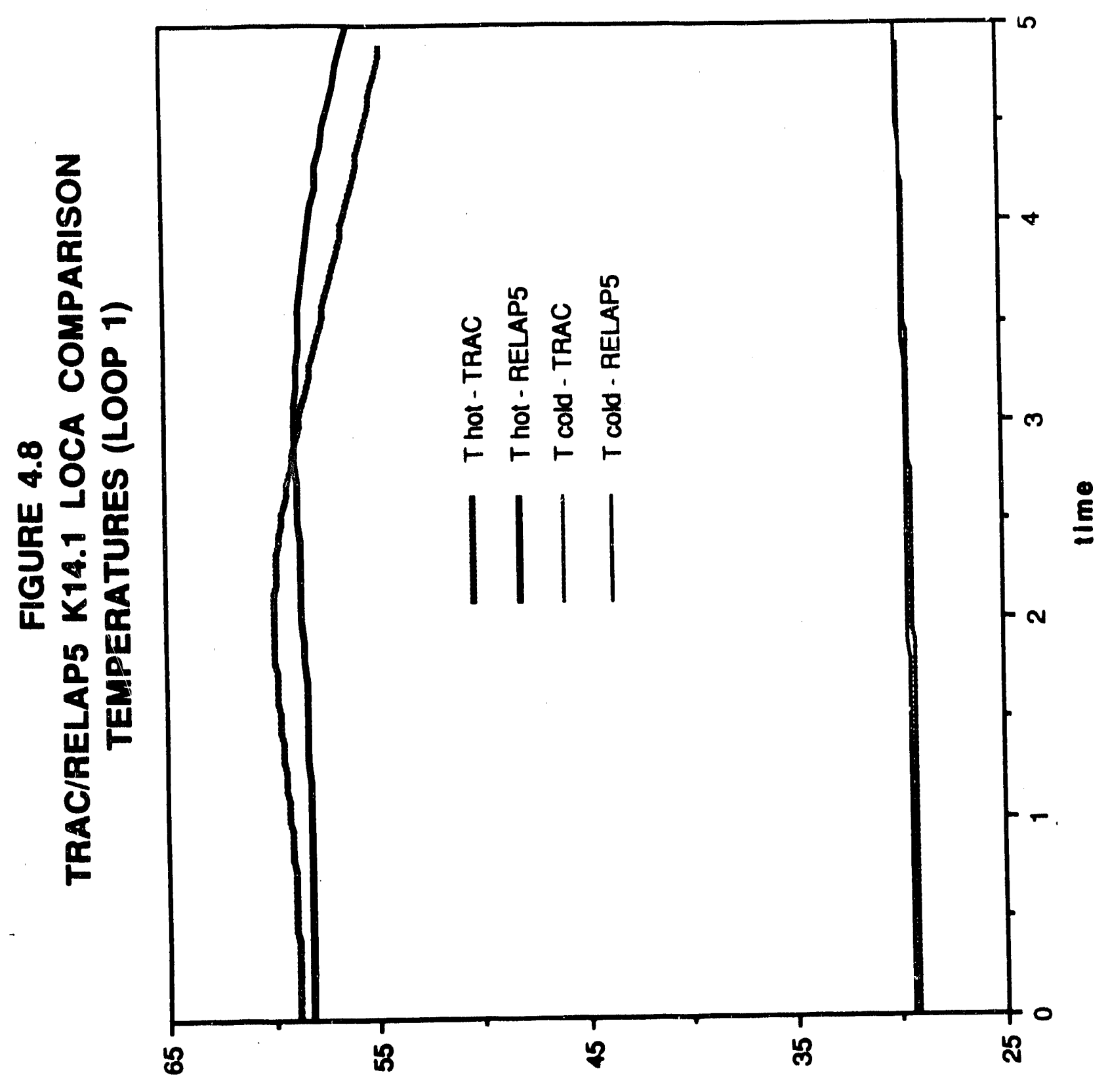

o scodbop ul esniasedwes 


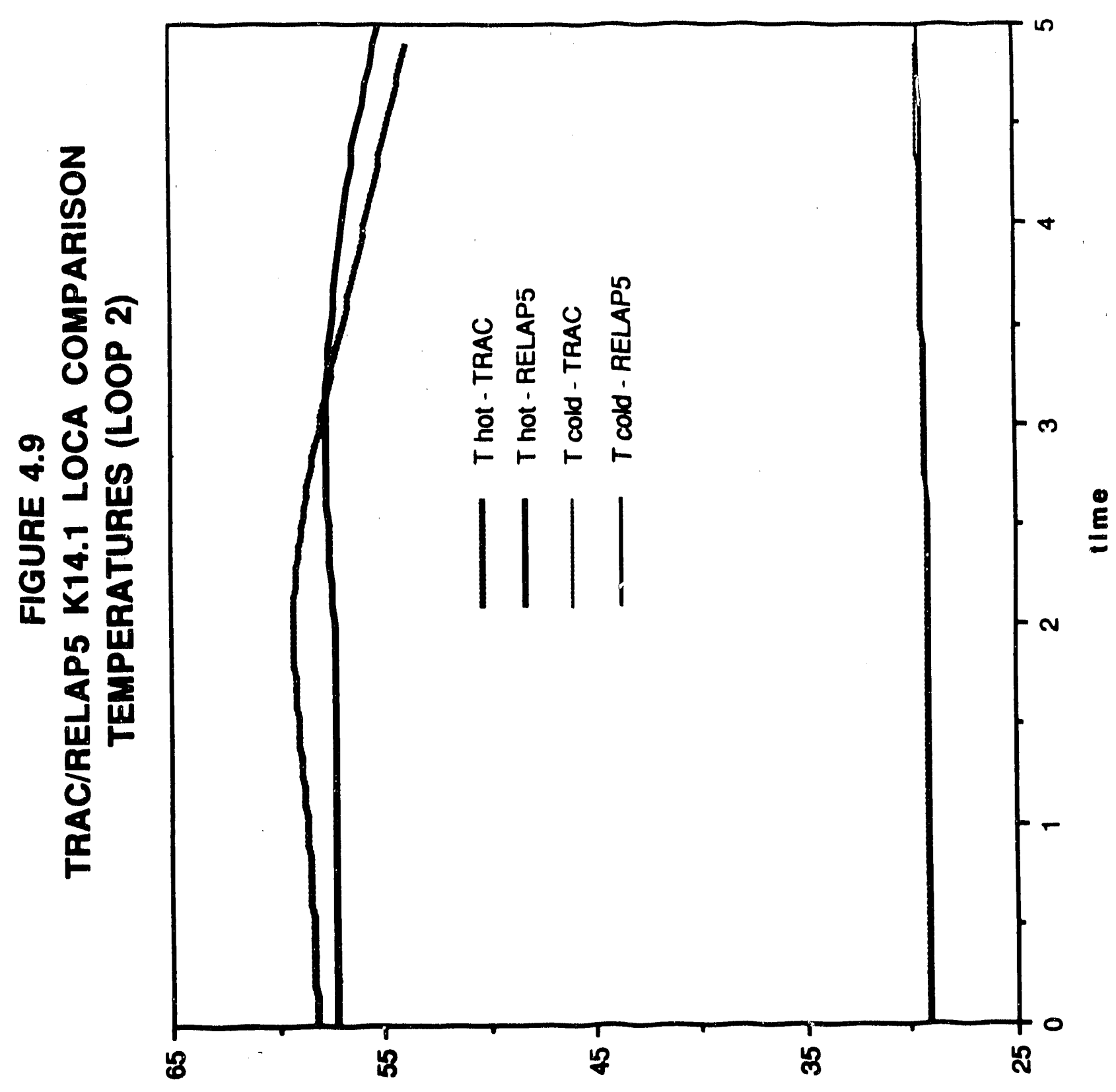

o soedbop u esnjesodwo! 


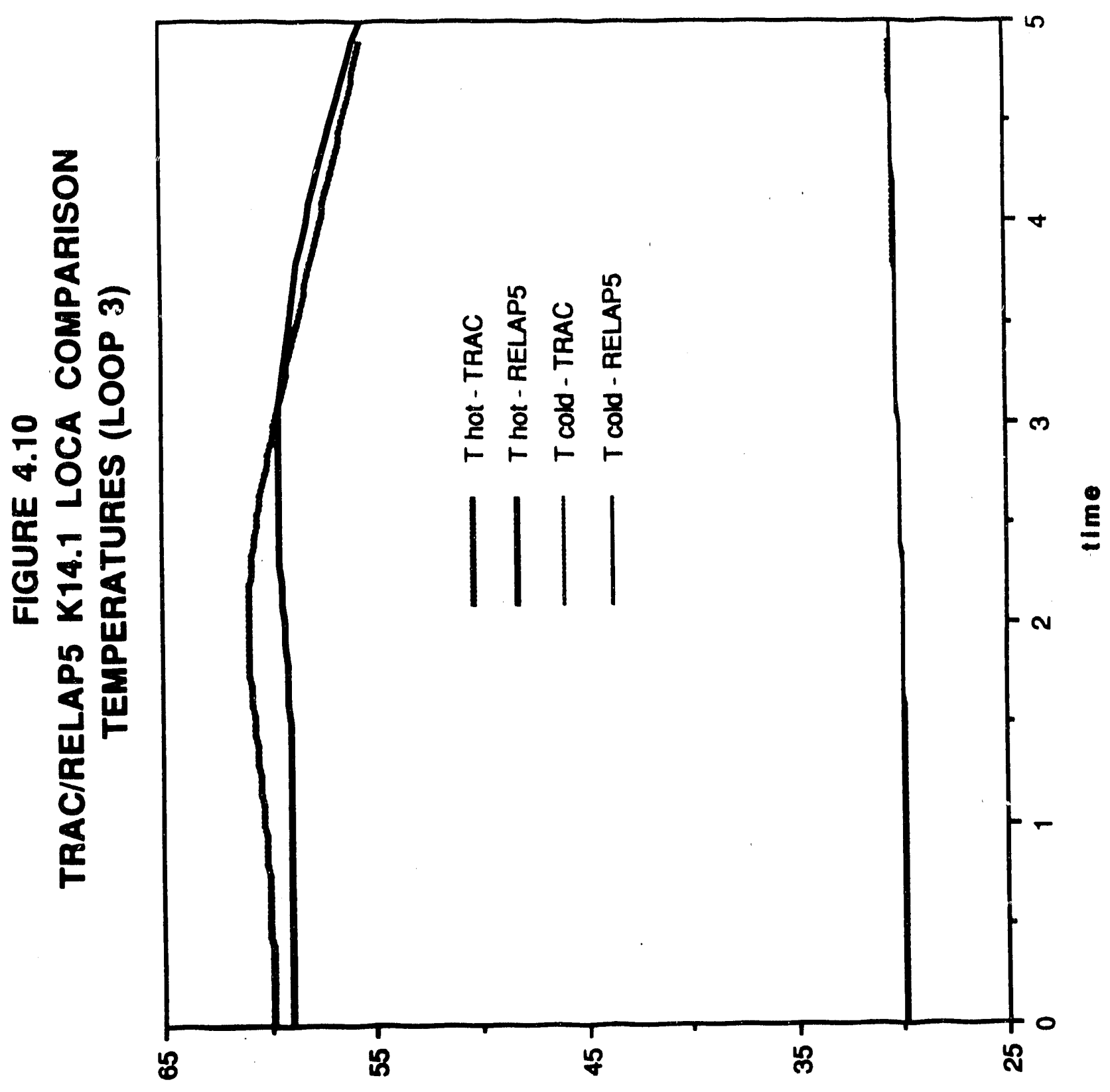

o scosbop uf annjesodwol 


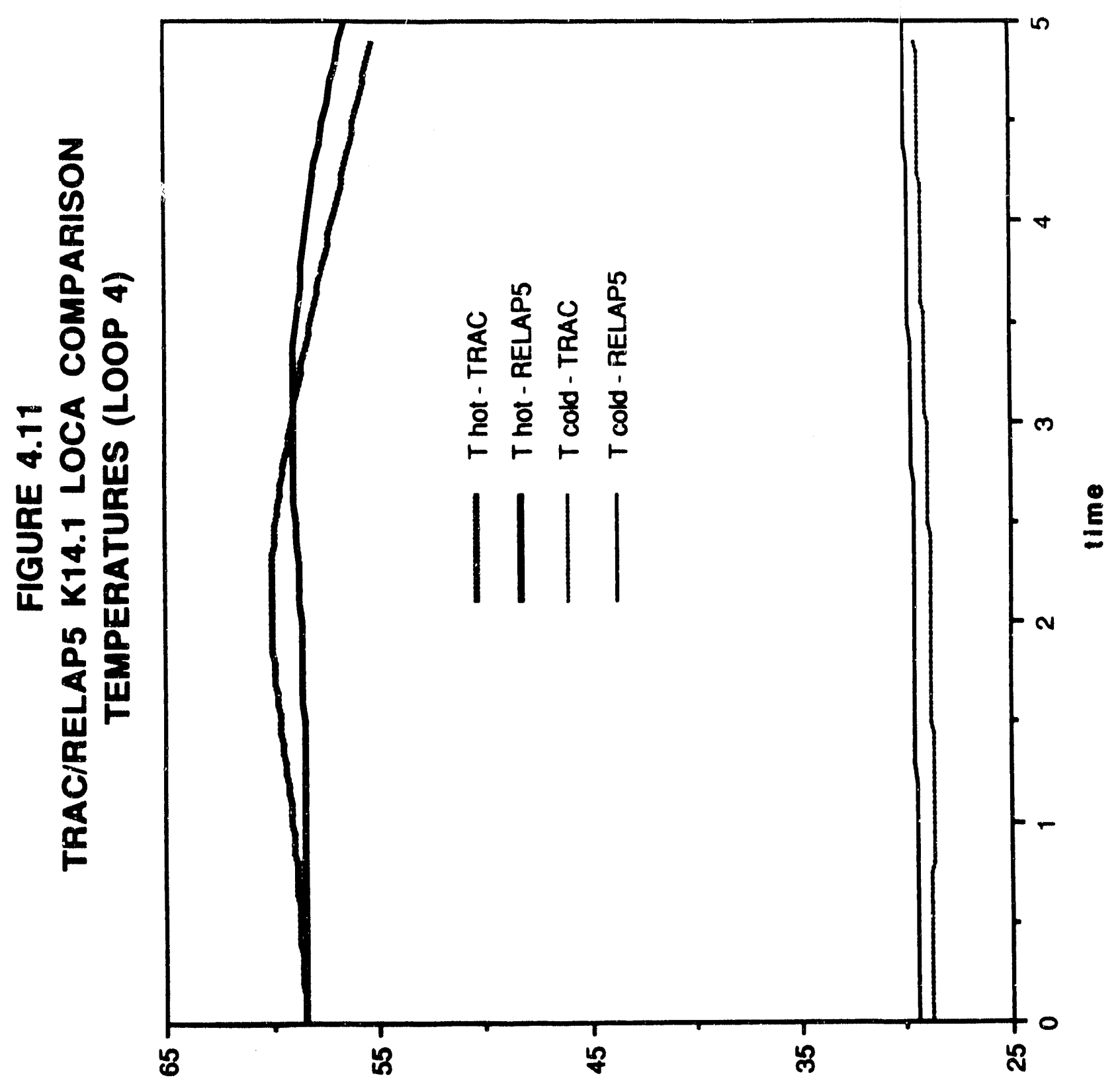

o seodbep ul esnlesedwel 


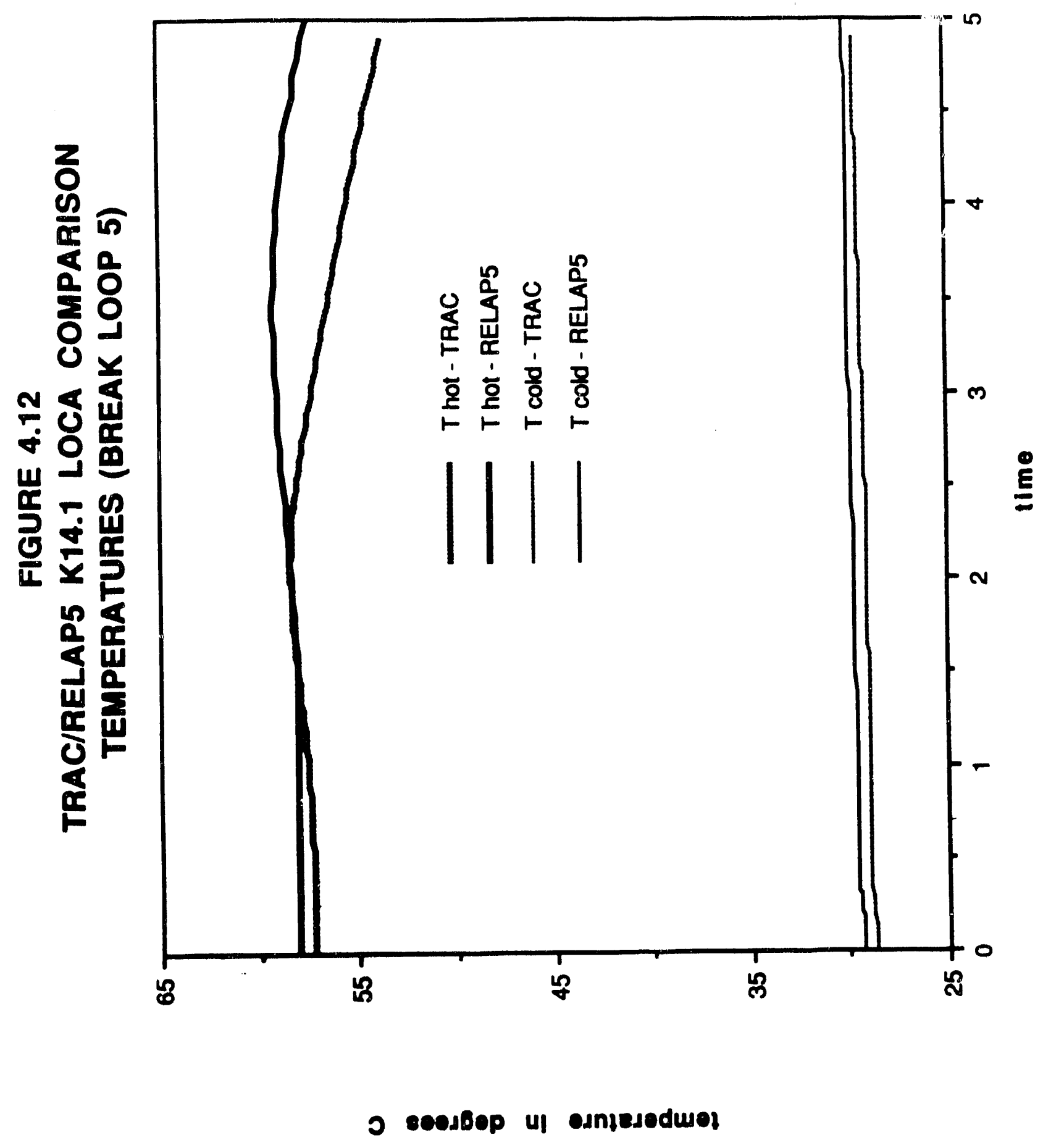




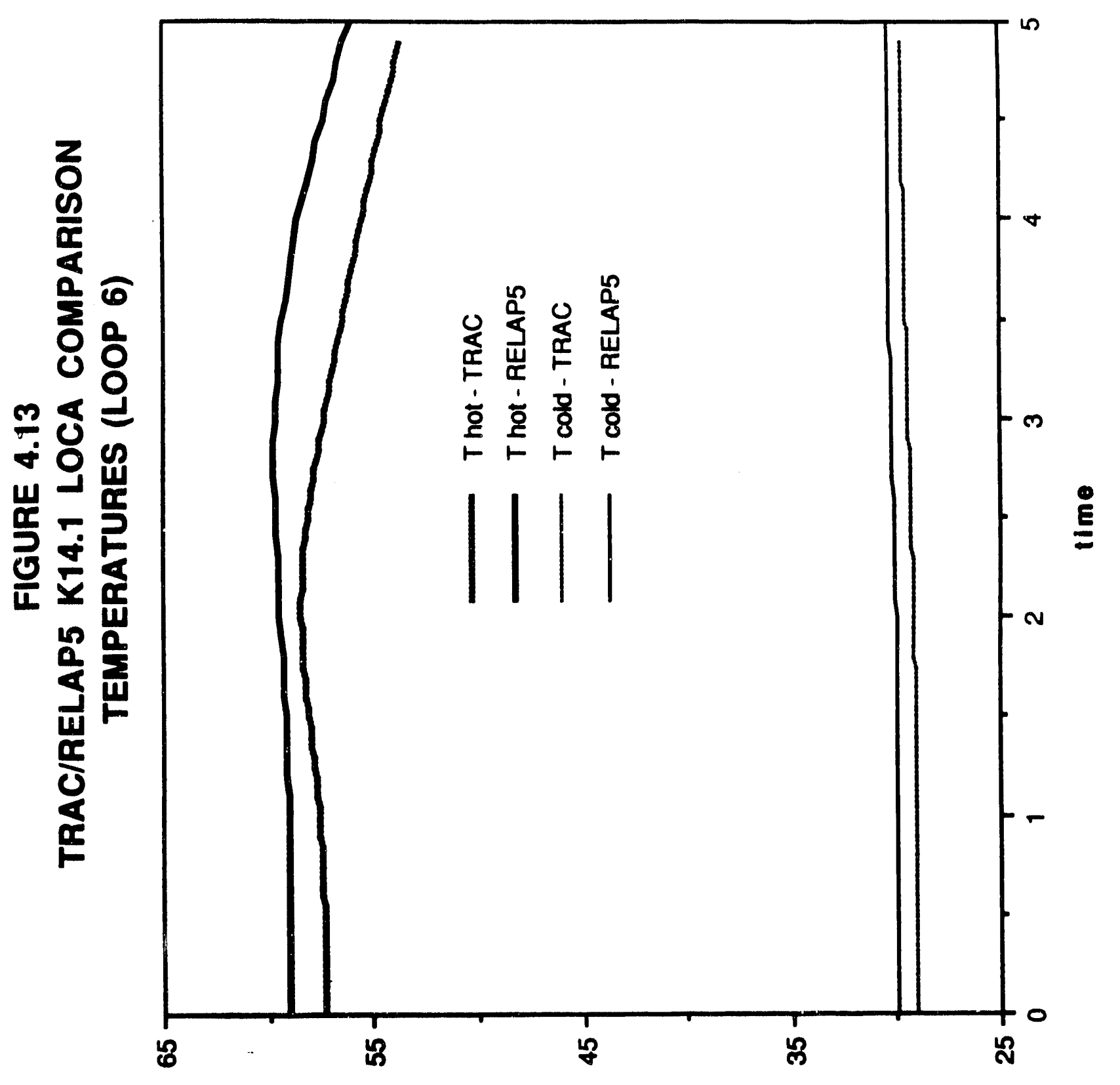

o soedbop ul osniesedwel 


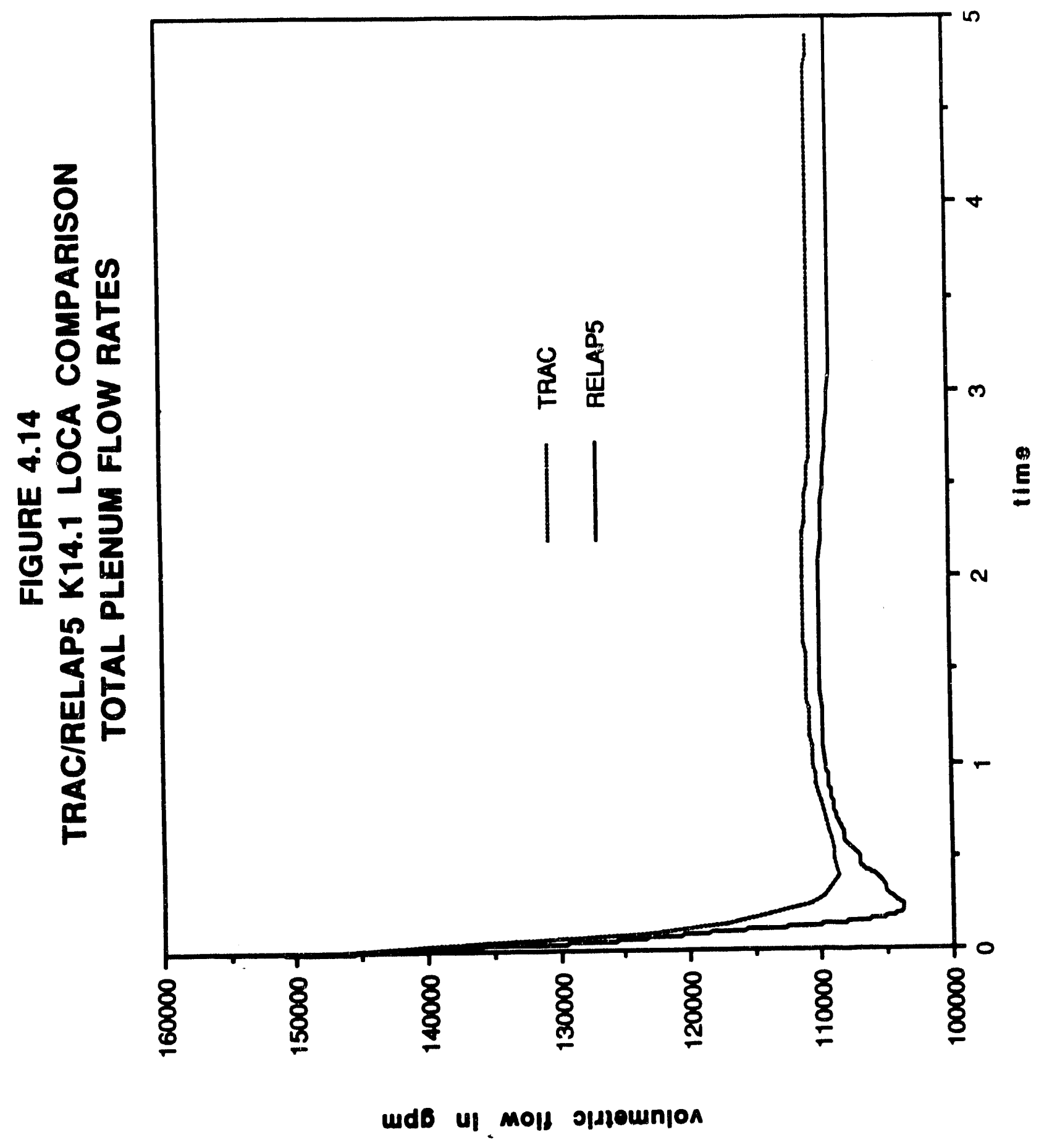




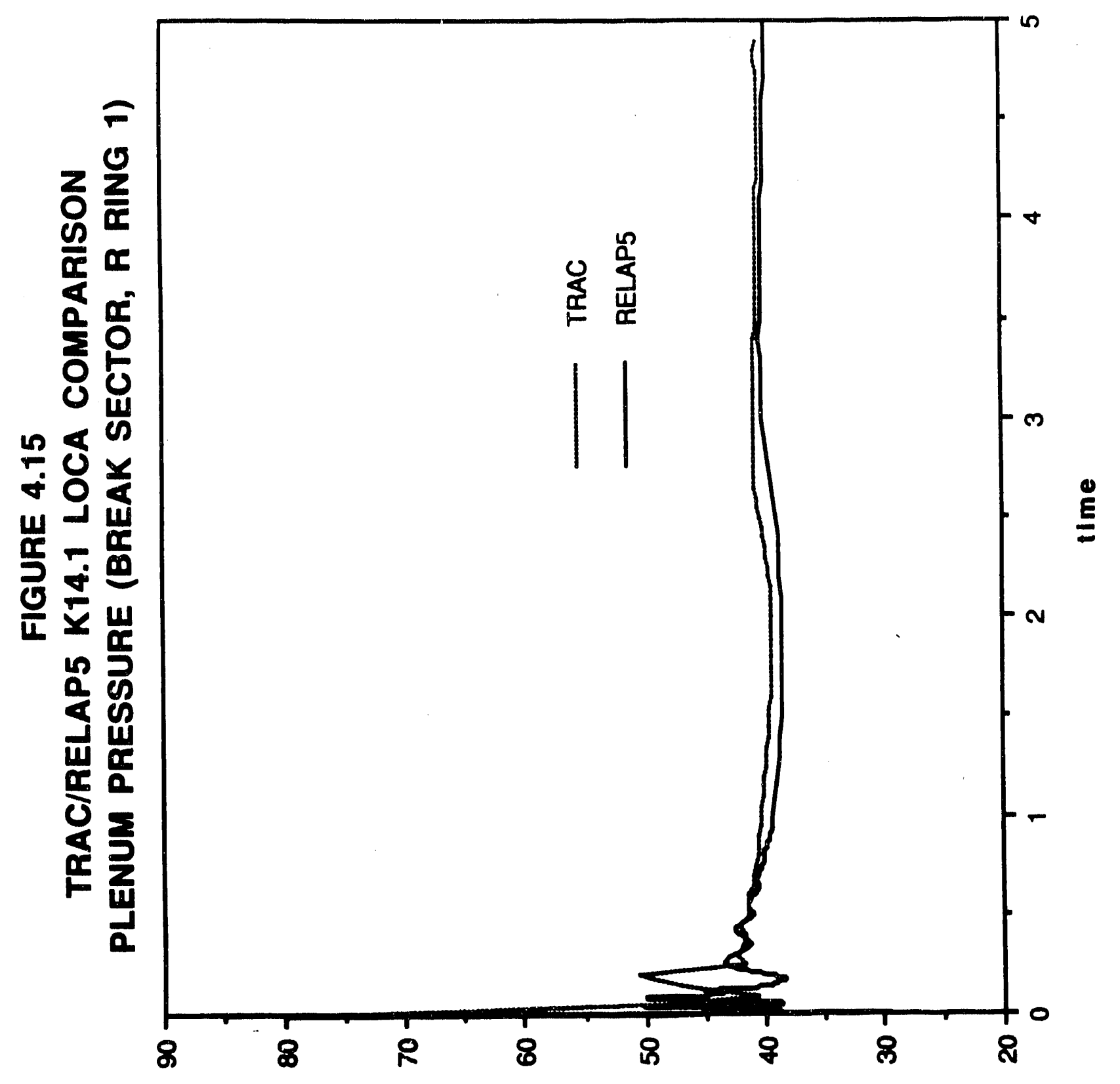

oled ul ounsesed 


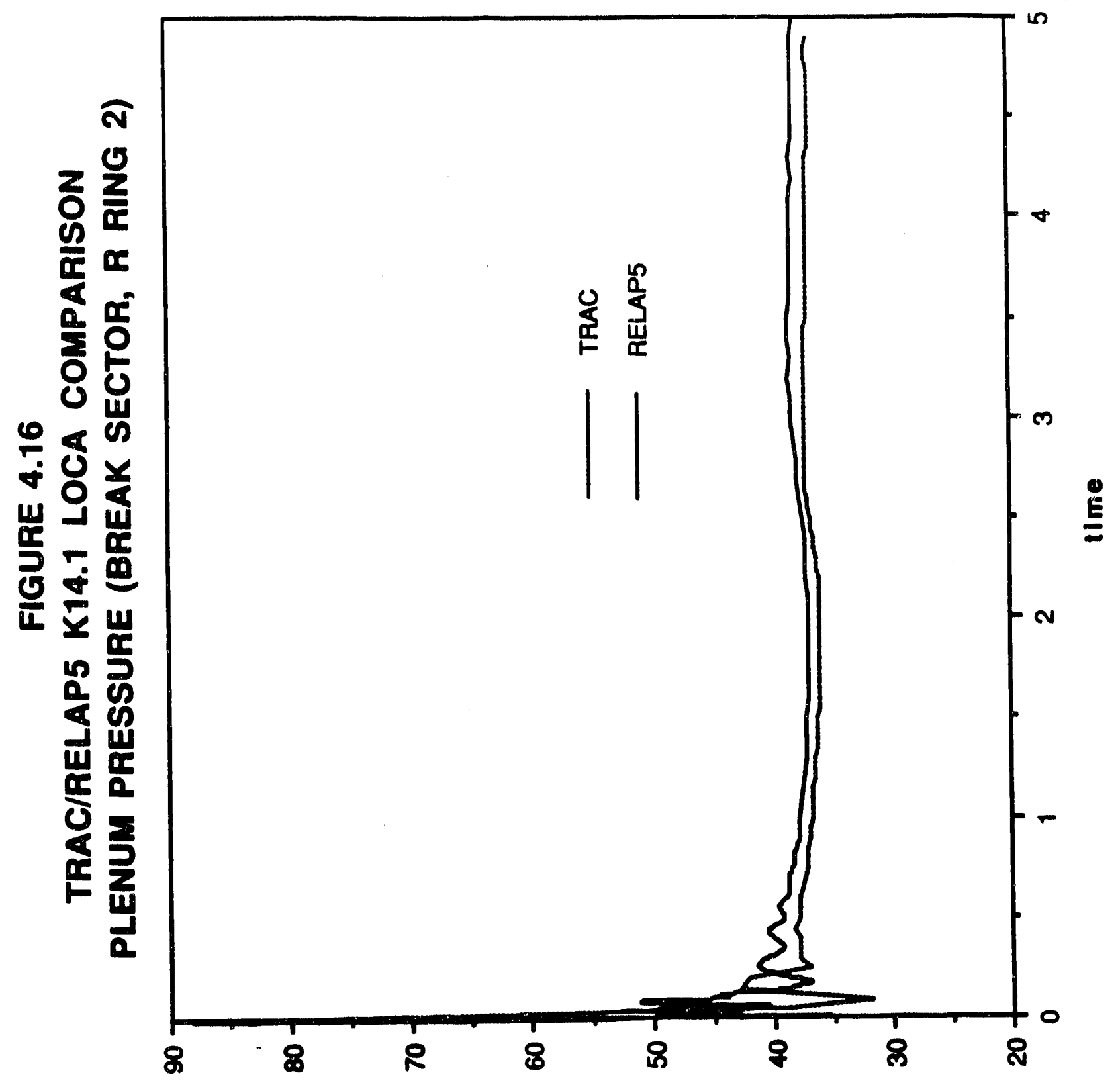

oled uf esnasesd 


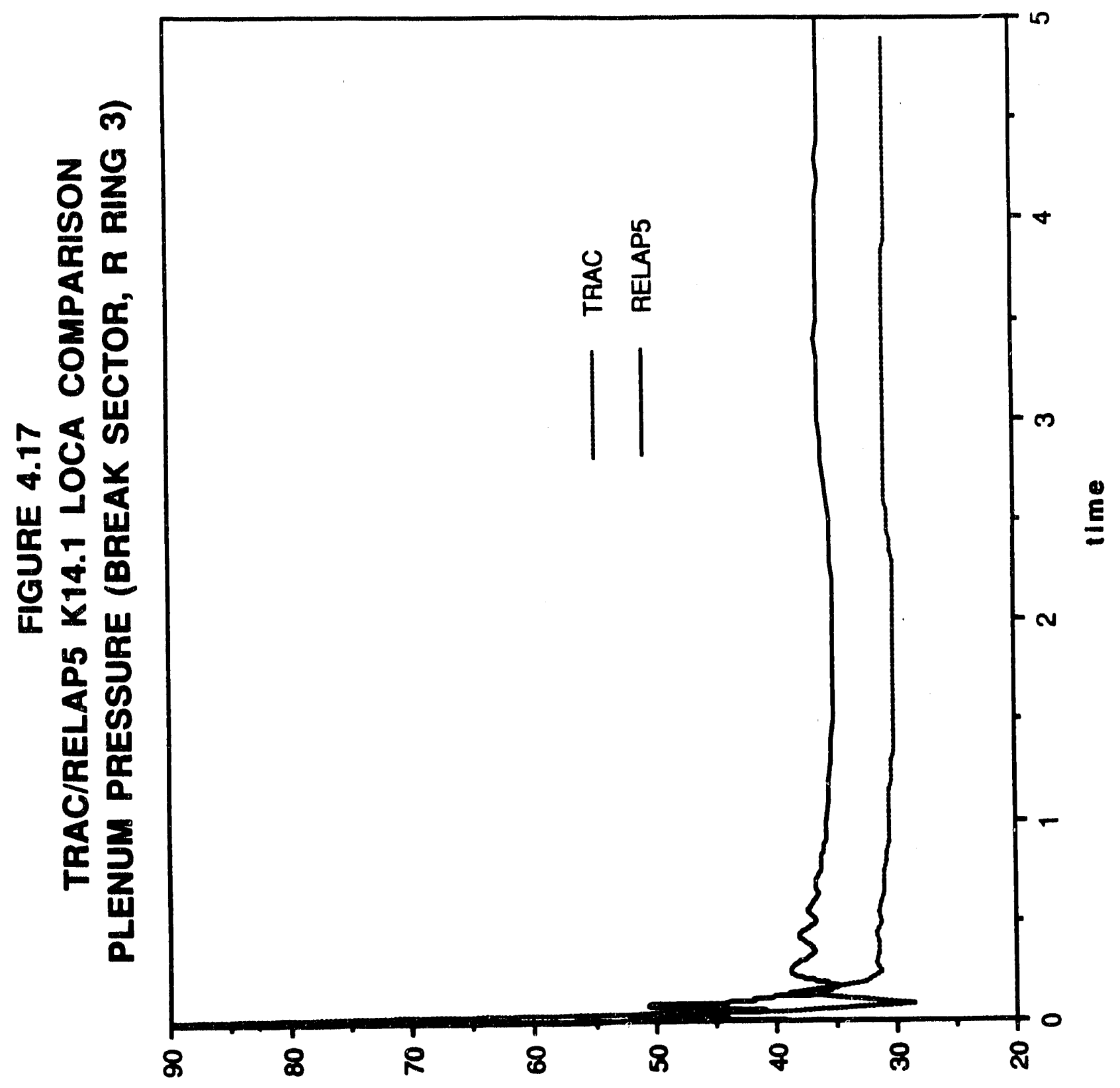

ojed u| odnosedd 


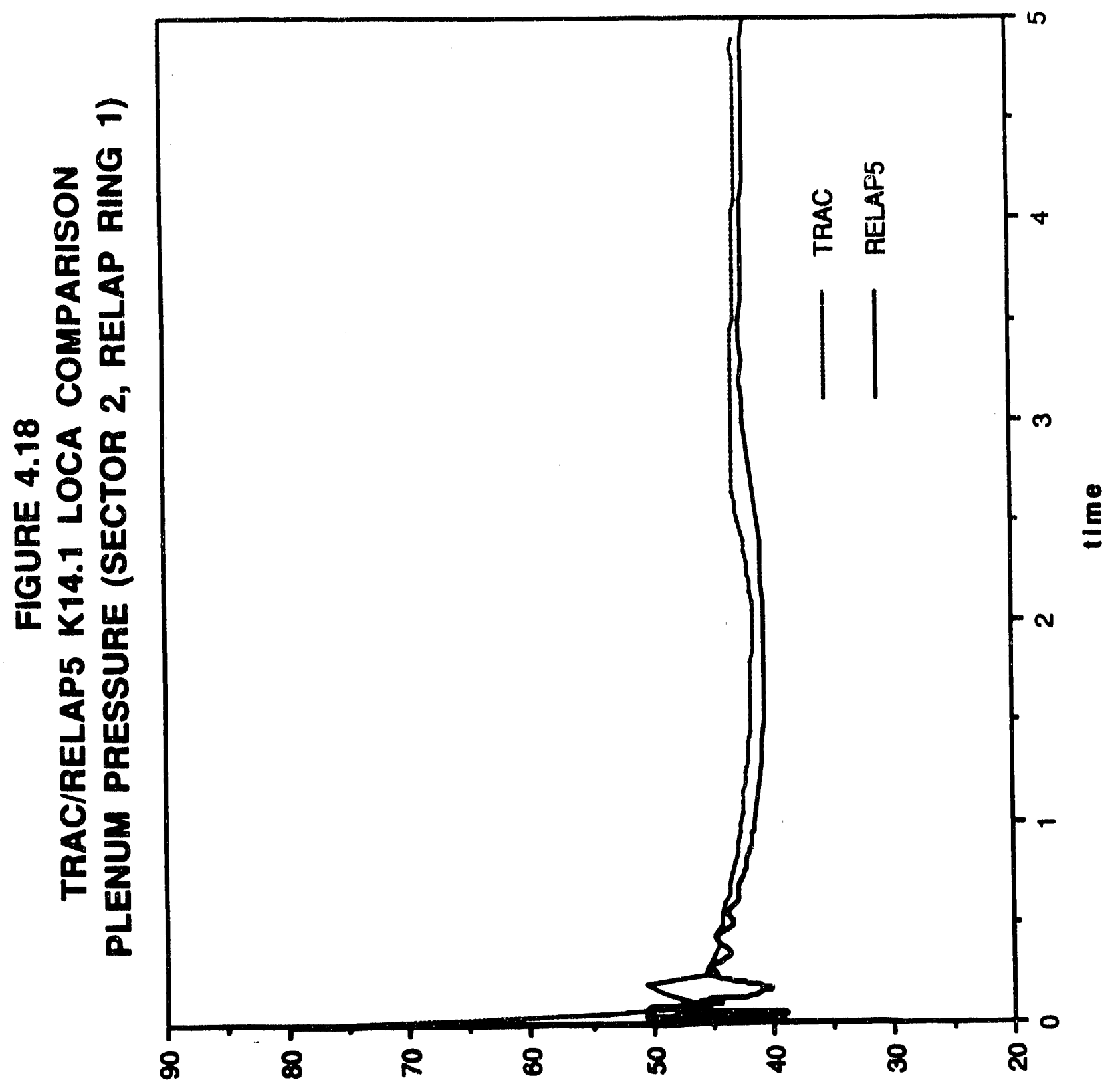

uyed u| eaneseasd 


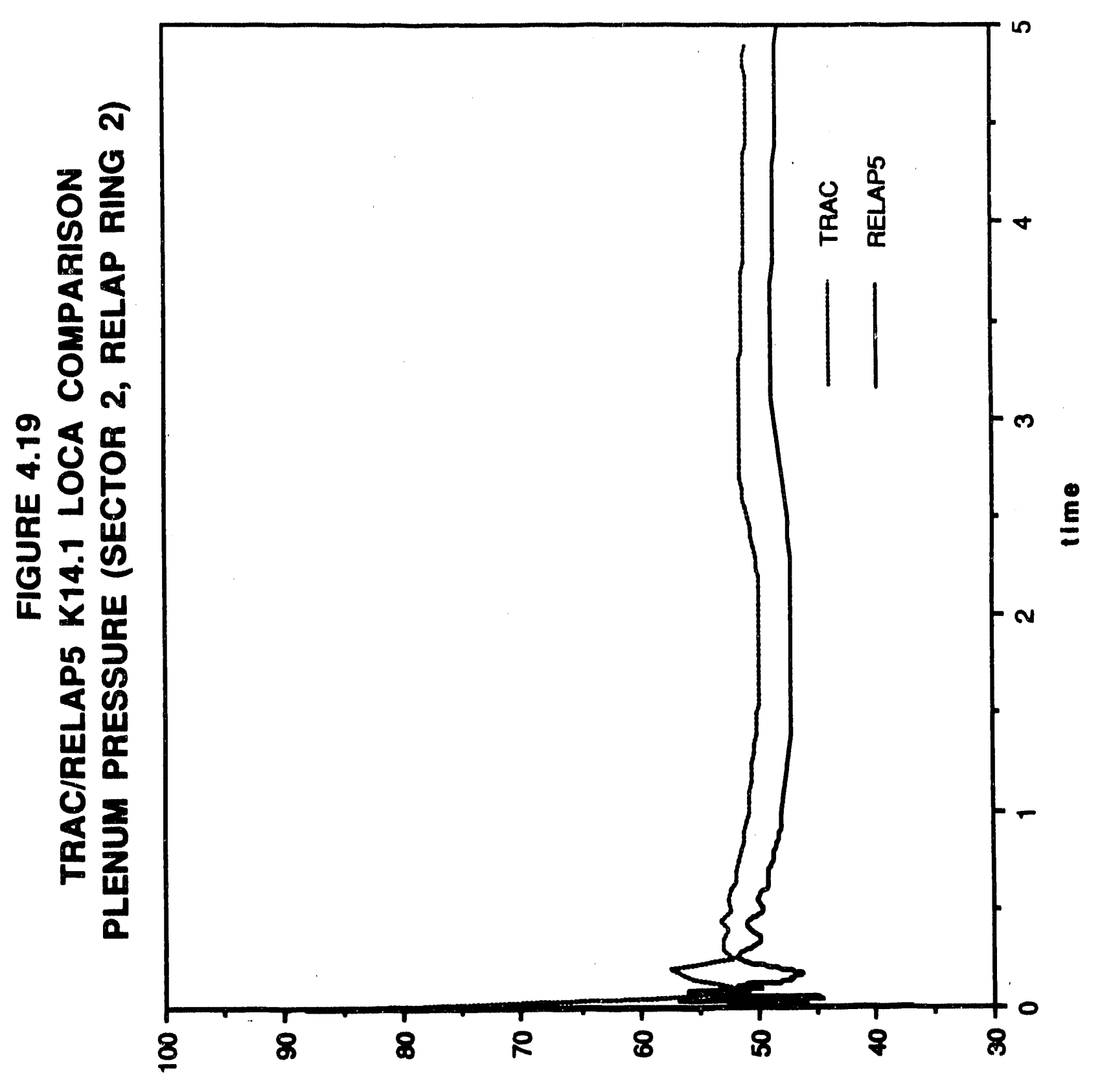

Oped uf esnseosd 


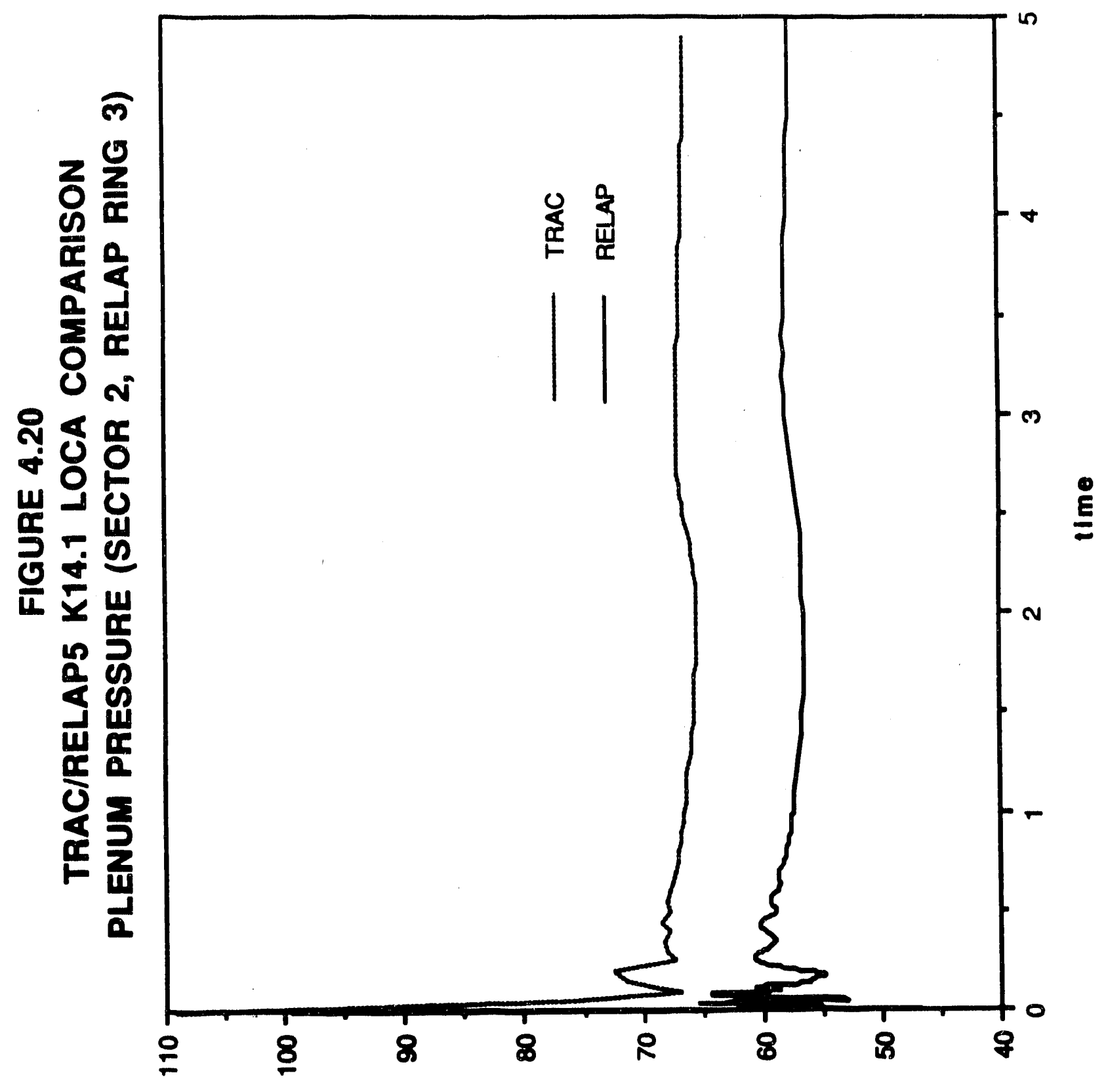

ojed ul esnesesd 


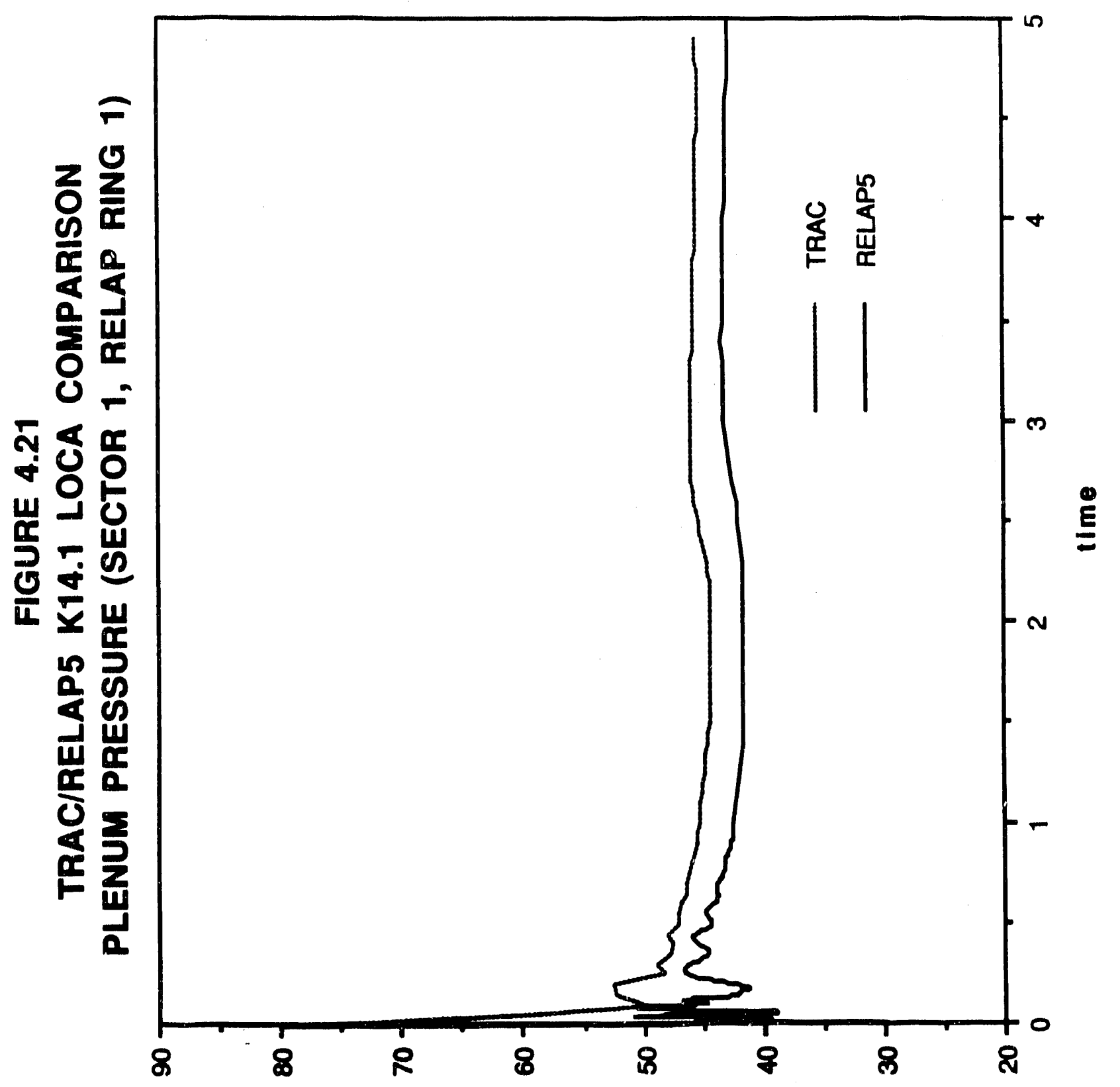

yed u/ odnseesd 


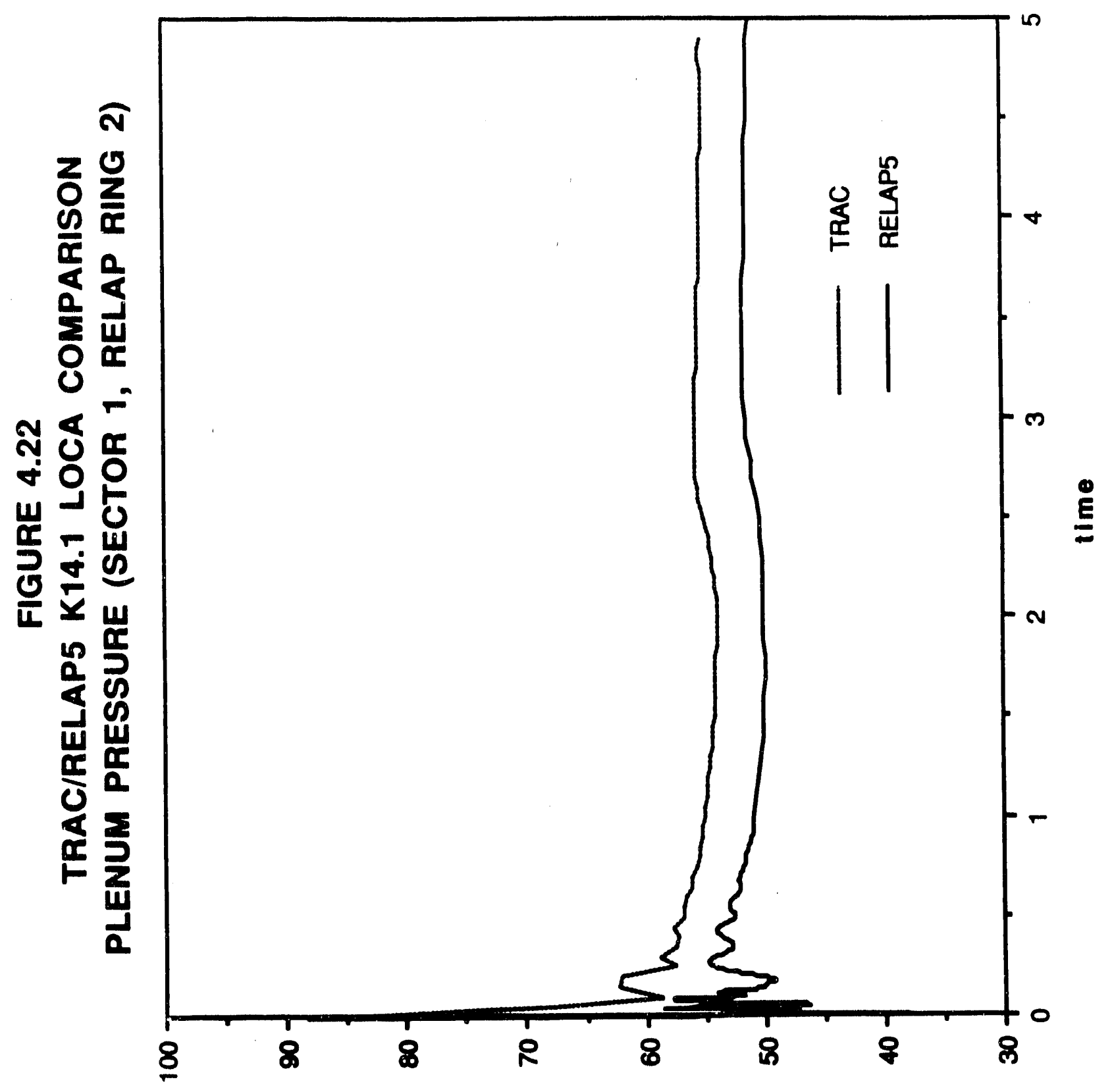

eped uf esnesesd 


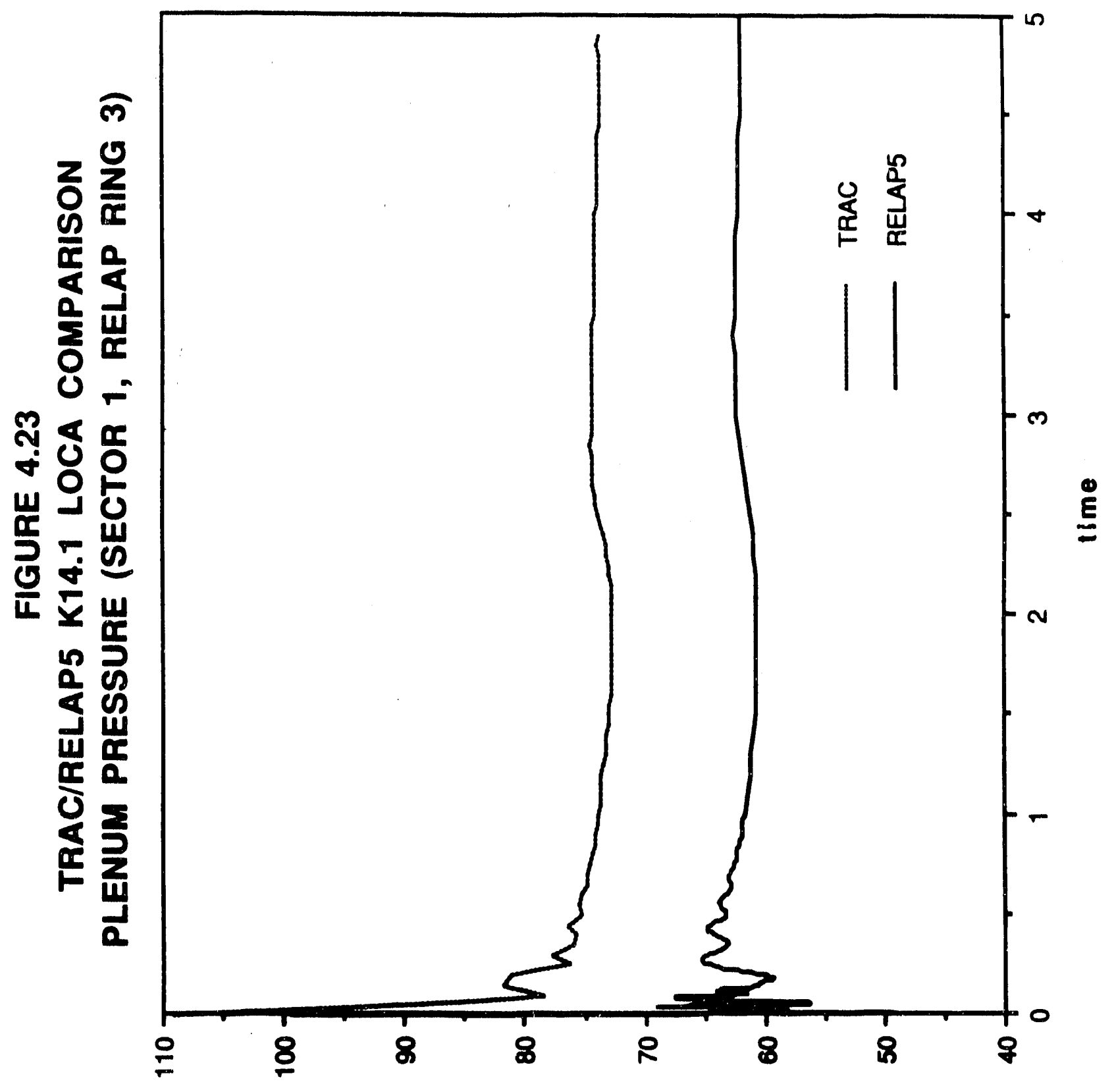

yod U/ asnesedd 


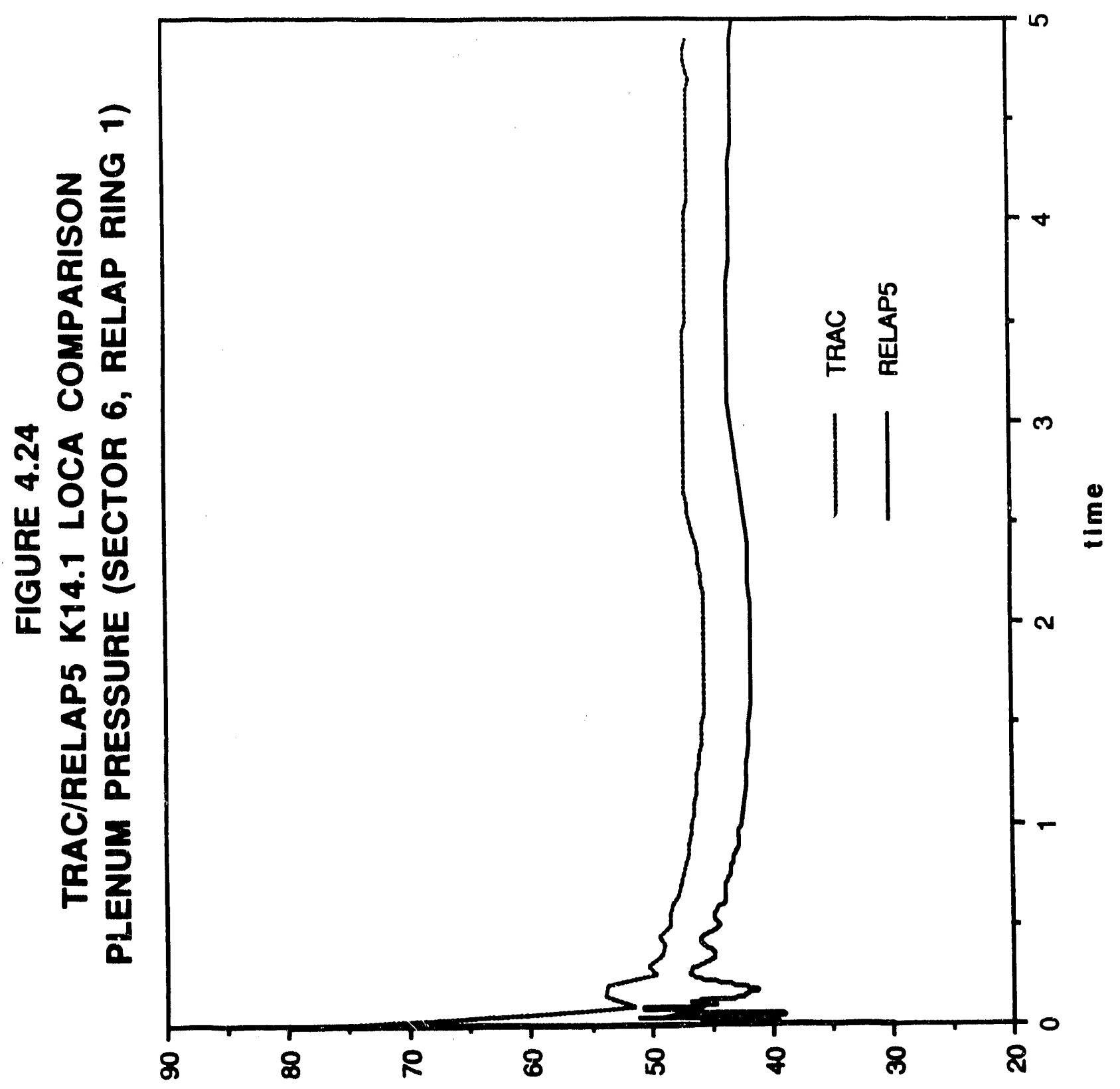

ejed ul asnseosd 


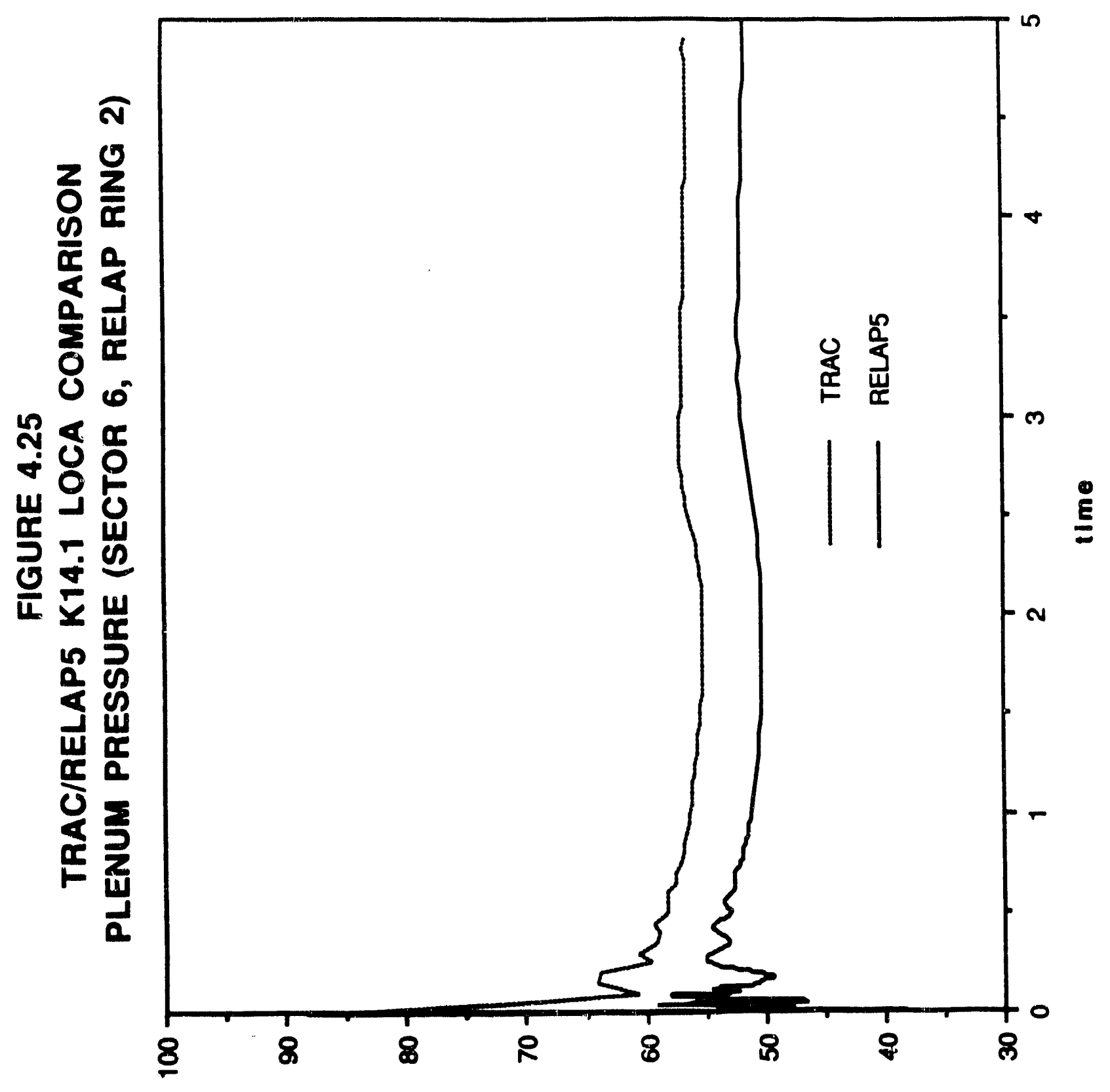

oled ul eanseodd 


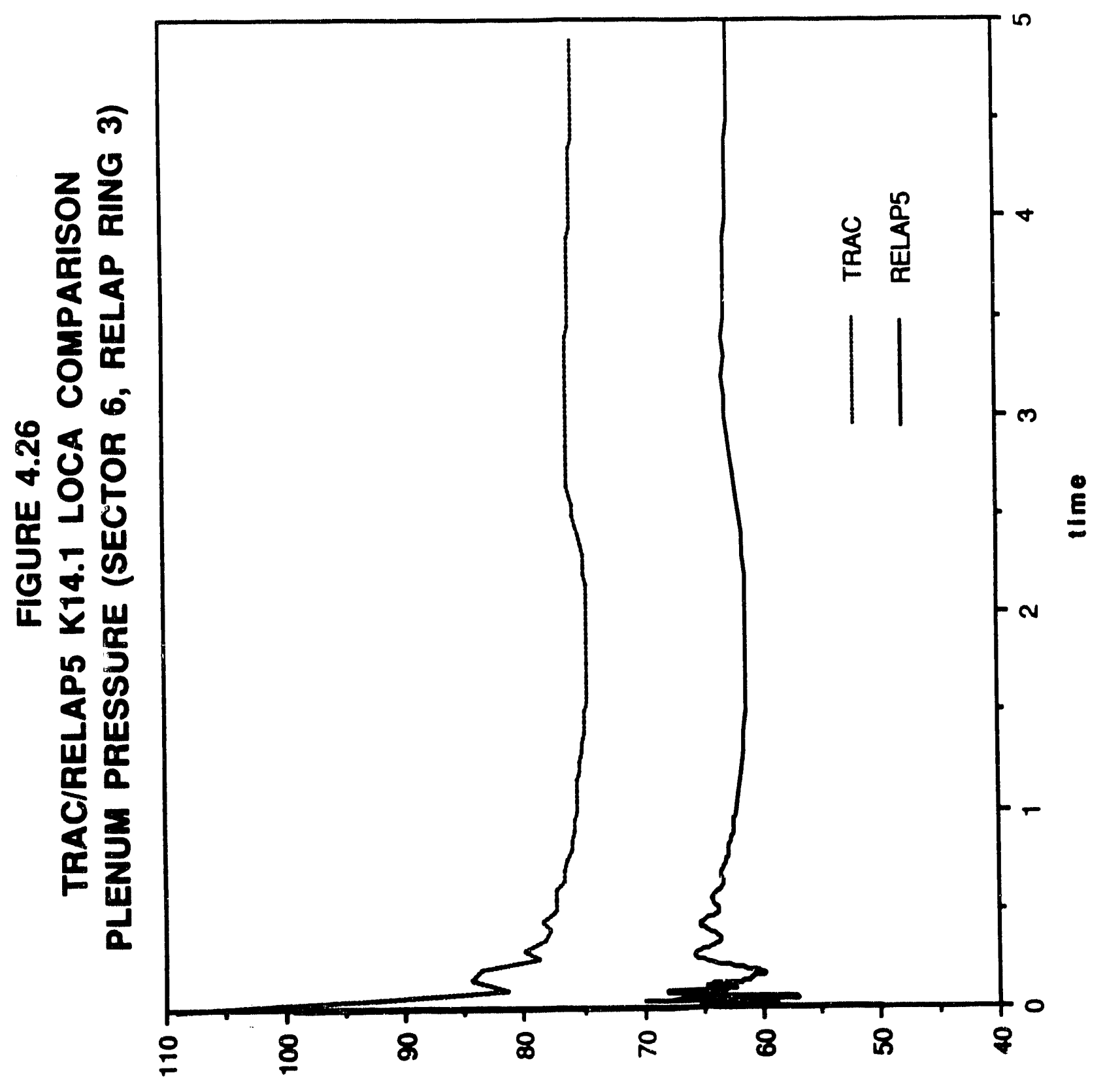

oled ul esnesejd 


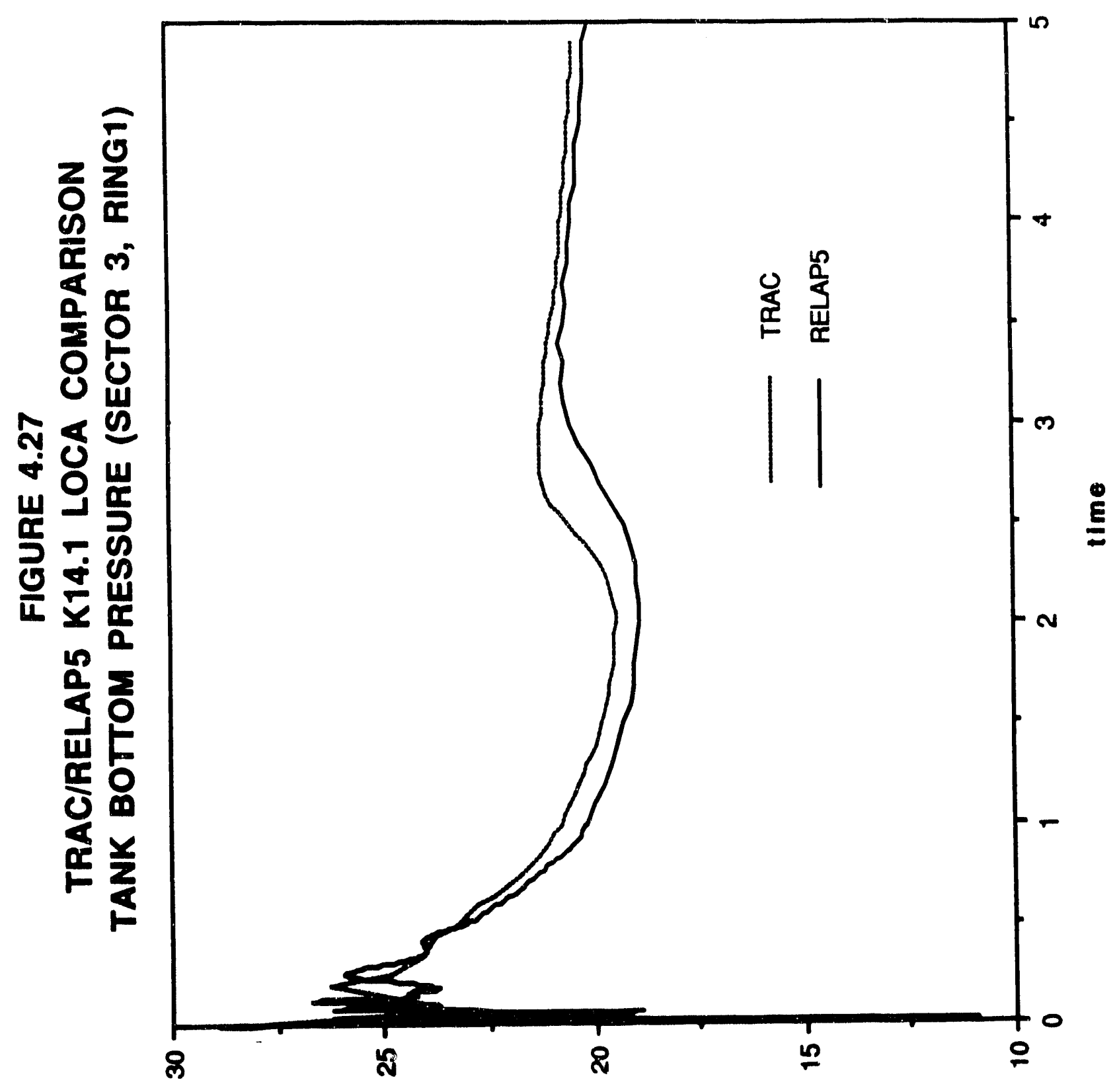

eled ul eansesed 


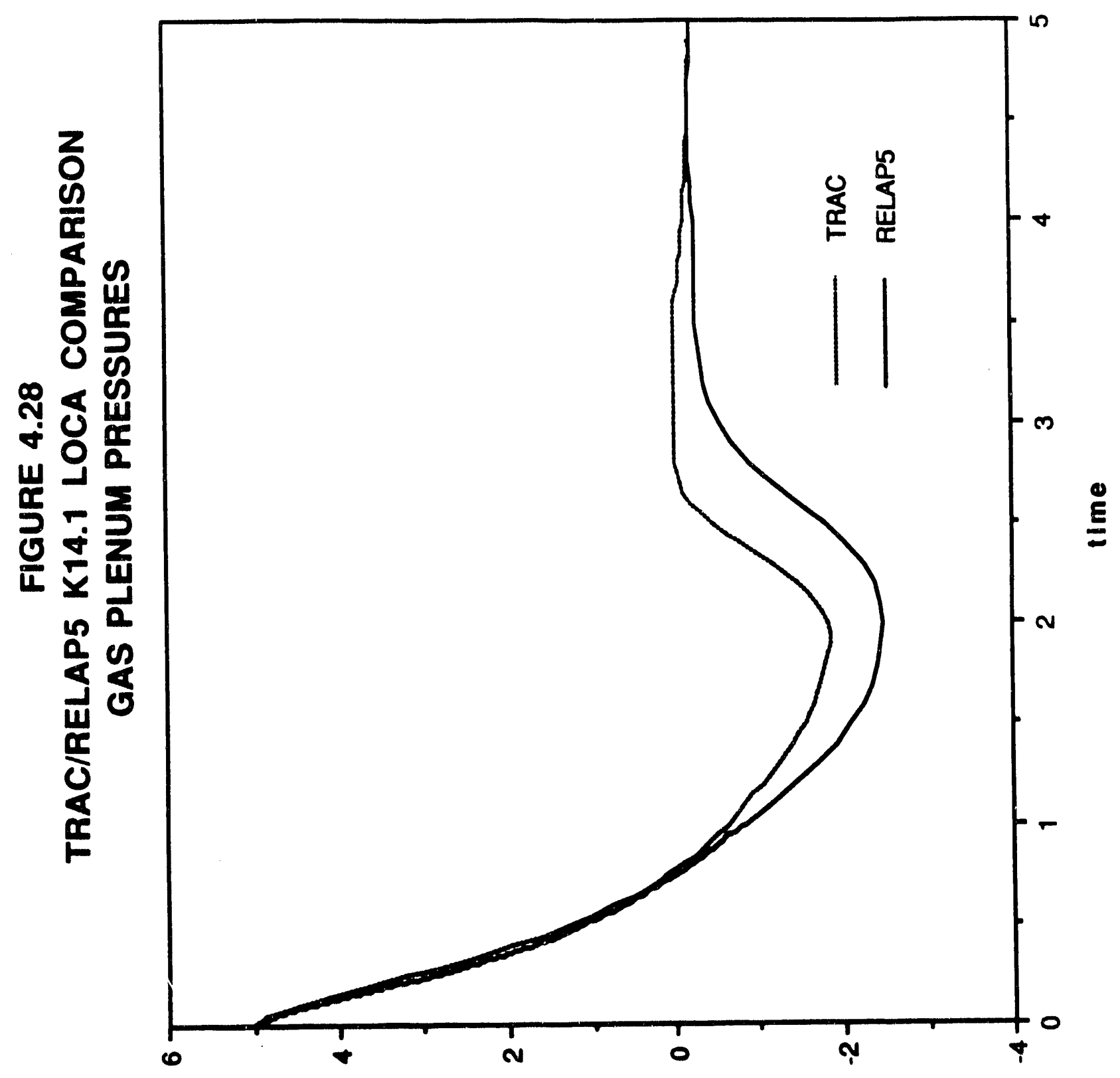

Bisd y| aunseadd 


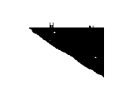

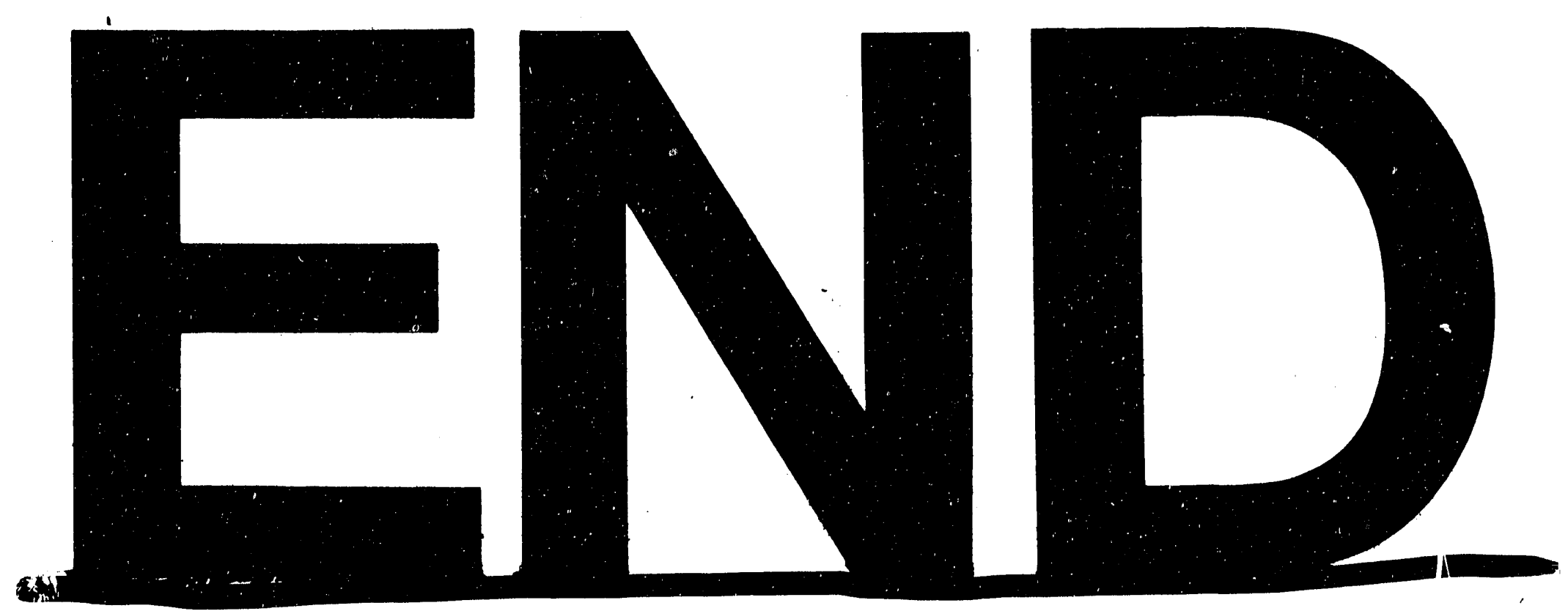

s.
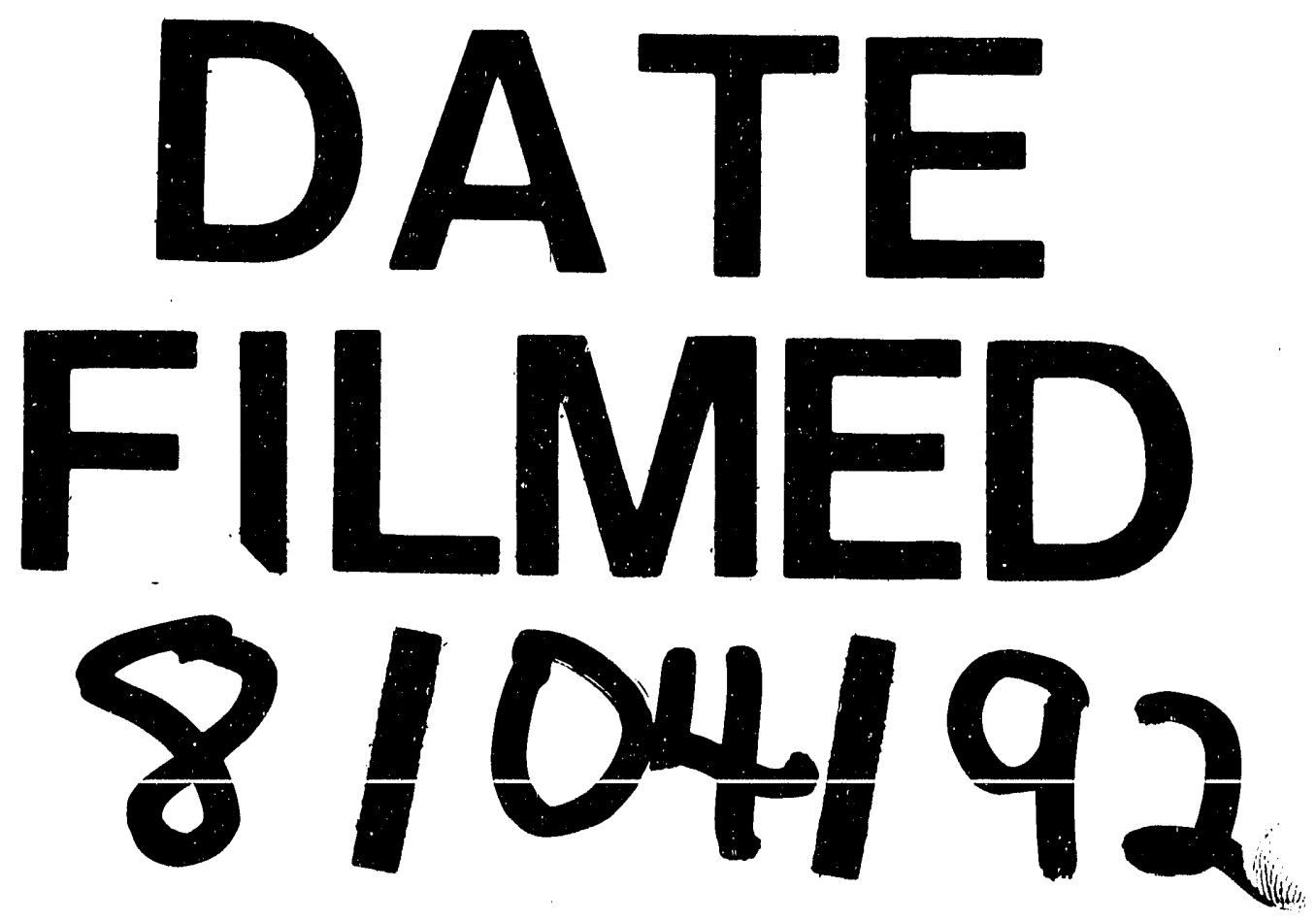
